\title{
Uso combinado de sistemas de informações geográficas para transportes e programação linear inteira mista em problemas de localização de instalações
}

\section{Combining geographic information systems for transportation and mixed integer linear programming in location-allocation problems}

\author{
Sílvia Maria Santana Mapa ${ }^{1}$ \\ Renato da Silva Lima²
}

\begin{abstract}
Resumo: O objetivo do trabalho é avaliar a qualidade das soluções para o problema de localização-alocação de instalações geradas por um SIG-T (Sistema de Informação Geográfica para Transportes), obtidas após a utilização combinada das rotinas Localização de Facilidades e Problema do Transporte, quando comparadas com as soluções ótimas obtidas a partir de modelo matemático exato baseado em Programação Linear Inteira Mista (PLIM), desenvolvido externamente ao SIG. Os modelos foram aplicados a três simulações: a primeira propõe a abertura de fábricas e alocação de clientes no Estado de São Paulo; a segunda envolve um atacadista e um estudo de localização de centros de distribuição e alocação dos clientes varejistas; a terceira localiza creches em um contexto urbano, alocando a demanda. Os resultados mostraram que, quando se considera a capacidade das instalações, o modelo otimizante PLIM chegou a apresentar, em um dos cenários simulados, resultados até $37 \%$ melhores do que o SIG, além de propor locais diferentes para abertura de novas instalações. Quando não se considera a capacidade, o modelo SIG se mostrou tão eficiente quanto o modelo exato PLIM, chegando exatamente às mesmas soluções.
\end{abstract}

Palavras-chave: Sistema de informações geográficas. Problemas de localização-alocação. Planejamento de transportes. Programação linear inteira mista.

\begin{abstract}
This study aims to evaluate the quality of the solutions for facility location-allocation problems generated by a GIS-T (Geographic Information System for Transportation) software. These solutions were obtained from combining the Facility Location and Transportation Problem routines, when compared with the optimal solutions, which were obtained using the exact mathematical model based on the Mixed Integer Linear Programming (MILP) developed externally to the GIS. The models were applied to three simulations: the first one proposes set up businesses and customers'allocation in the state of São Paulo; the second involves a wholesaler and an investigation of distribution center location and retailers' allocation; and the third one locates day-care centers in an urban context allocating the demand. The results showed that when the facility capacity is considered, in addition to determine different locations for the new facilities, the optimal MILP model can produce results that are 37\% better than those of GIS.
\end{abstract}

Keywords: Geographic information system. Location-allocation problems. Transportation planning. Mixed integer linear programming.

\section{Introdução}

Problemas de localização-alocação de instalações são, em geral, problemas complexos, por envolverem um grande número de variáveis e grandes volumes de dados. À medida que a complexidade do problema aumenta, os estudos de localização necessitam de novas tecnologias de informação, que permitem tratar os sistemas de forma efetivamente integrada (LACERDA, 1999). A abordagem de modelos de localização de instalações tem sido proposta por meio de ferramentas de auxílio à decisão espacial, principalmente quando uma base de dados geograficamente referenciada se encontra disponível. Neste caso, os Sistemas

\footnotetext{
${ }^{1}$ Instituto Federal de Educação, Ciência e Tecnologia de Minas Gerais - IFMG,

Av. Michael Pereira de Souza, 3007, Campus Congonhas, Campinho, CEP 36415-000, Congonhas, MG, Brasil, e-mail: silvia.mapa@ifmg.edu.br

2 Instituto de Engenharia de Produção e Gestão - IEPG, Universidade Federal de Itajubá - UNIFEI,

Av. BPS, 1303, Pinheirinho, CP 50, CEP 37500-903, Itajubá, MG, Brasil, e-mail: rslima@unifei.edu.br 
de Informações Geográficas (SIG) são de vital importância na coleta e análise desses dados, pois integram uma sofisticada interface gráfica a uma base de dados geograficamente referenciada, constituindo-se em poderosas ferramentas de análise e planejamento espacial (LIMA, 2003). Os Sistemas de Informações Geográficas aplicados ao Transporte (SIG-T) são uma classe especial dos SIG, sendo aplicados na área de planejamento e operação de transportes. Dentre suas diversas funcionalidades, possuem módulos dedicados à localização de facilidades. Nada mais natural, então, do que utilizar as ferramentas de um SIG-T para estudar as melhores localizações de facilidades, públicas ou privadas, tais como fábricas, centros de distribuição, escolas ou creches, e as melhores distribuições dos clientes a estas unidades, buscando reduzir os custos de deslocamento ou transporte.

Diversos softwares são utilizados no auxílio a problemas de localização. Porém, a maioria deles acaba funcionando como uma "caixa preta": seus métodos de solução não são transparentes, restando aos usuários em geral a hipótese de acreditar na eficiência dessas soluções. A partir de experiências anteriores efetuadas nos módulos de localização-alocação do SIG-T TransCAD ${ }^{\circledR}$, (versão 4.8) constatou-se que este resolve o problema, porém de forma indireta, em duas etapas. A primeira engloba a rotina Facility Location (FL), que identifica as melhores localizações para as instalações (propondo a abertura de novas unidades e/ou o fechamento de já existentes), e procede a alocação entre demanda e oferta, porém sem levar em consideração a capacidade máxima de operação das instalações. Para impor esta restrição de limite de capacidade, faz-se necessário uma segunda etapa, na qual se submete a solução da rotina Facility Location à rotina Transportation Problem (TP). Sendo assim, a solução da rotina FL se torna a entrada da rotina TP, que irá realocar a demanda à oferta segundo o critério de limite máximo de capacidade das instalações. Porém, esta segunda rotina não mais admite a abertura ou fechamento das instalações previamente geradas na rotina FL, ficando pré-condicionada àquela configuração inicial, fator que claramente pode comprometer a qualidade da solução final, visto que a escolha de abertura/fechamento de novas instalações é certamente condicionada às suas respectivas capacidades. Adicionalmente, há que se considerar que ambas as rotinas trabalham com algoritmos heurísticos na busca das soluções. Consequentemente, não se garante que a solução encontrada após a utilização das rotinas seja a solução ótima, o que só se saberia ao certo com a resolução do problema via algoritmo otimizante.

Esse é o ponto de partida para o presente trabalho, cujo objetivo é avaliar a qualidade das soluções para o problema de localização-alocação de instalações geradas por um SIG-T, obtidas após a utilização combinada das rotinas FL e TP, quando comparadas com as soluções ótimas, obtidas a partir de modelo matemático exato baseado em Programação Linear Inteira Mista (PLIM), desenvolvido externamente ao SIG. O modelo PLIM pode realizar a localização e alocação das instalações aos seus clientes obedecendo aos limites de capacidade máxima destas instalações de forma simultânea, ao contrário do uso das rotinas combinadas do SIG.

$\mathrm{Na}$ metodologia de pesquisa do trabalho, classificada como modelagem e simulação, tanto o modelo SIG quanto o modelo PLIM foram aplicados a três simulações, de diferentes níveis de complexidade. A primeira propõe a abertura de fábricas e alocação de clientes em 18 principais municípios paulistas. A segunda envolve o estudo de localização de centros de distribuição de um atacadista e alocação de seus clientes varejistas nos Estados de MG e SP. $\mathrm{Na}$ terceira, o objetivo é localizar creches e alocar a demanda (crianças de 0 a 3 anos) na cidade de São Carlos, SP. Os resultados dos modelos SIG e PLIM são então comparados e analisados. O trabalho está estruturado da seguinte maneira: depois desta introdução, apresentam-se na seção 2 algumas considerações sobre o referencial teórico utilizado; a seção 3 apresenta a metodologia de pesquisa adotada, seguidas das três simulações na seção 4; a seção 5 apresenta a análise geral das três simulações; e a seção 6 traz as conclusões do trabalho, seguida da lista com as referências bibliográficas utilizadas.

\section{Referencial teórico}

\subsection{Localização de instalações}

Os problemas de localização de instalações (do inglês, Facility Location) envolvem escolher o melhor local para uma ou mais instalações dentro de um conjunto de locais possíveis, a fim de fornecer um alto nível de serviço aos clientes, minimizar custos de operação, ou maximizar lucros. O que se pretende obter é uma solução, se possível ótima, que minimize o custo total de instalações e transportes (BALLOU, 2006).

Apesar da teoria da localização ter seu início ainda no século XVIII, poucas foram as aplicações realmente desenvolvidas até meados de 1960, momento em que a questão ganha interesse e uma ampla gama de trabalhos começa a ser desenvolvida e publicada (OWEN; DASKIN, 1998). Desde então, o problema de localização de instalações tem sido amplamente tratado na literatura (PIZZOLATO et al., 2004), não sendo intenção deste trabalho esgotar o assunto, mas apenas apresentar os tópicos mais relevantes ao escopo desta pesquisa. Owen e Daskin (1998) apresentam uma revisão de literatura sobre os modelos 
de localização, classificando-os de acordo com os principais modelos (Quadro 1).

Aplicações de problemas de localização de instalações ocorrem nos setores privado e público, com o objetivo de estar o mais próximo possível da demanda, com o intuito de reduzir custos em transportes, maximizar a área de cobertura, aumentar o nível de acessibilidade da demanda ou reduzir ao máximo os custos com instalações, seja pela escolha de uma localização devido ao custo financeiro, ou pela quantidade de instalações a serem estabelecidas.

\subsection{Sistemas de informações geográficas (SIG)}

Segundo Church (2002) e Fleury, Wanke e Figueiredo (2000), os Sistemas de Informações Geográficas podem ser definidos como uma coleção organizada de hardware, software, pessoal qualificado e dados geográficos, com o objetivo de gerenciar banco de dados, efetuando operações de inserção, armazenagem, manipulação, remoção, atualização, análise e visualização de dados, tanto espaciais como não espaciais (dados de atributos), funcionando como uma valiosa ferramenta em estudos de planejamento e gerenciamento. Entender o SIG como somente um software é perder de vista o papel crucial que ele pode desempenhar, em um processo amplo de tomada de decisão. Segundo Lima (2003), desde a década de 1990 tem havido um vasto e crescente interesse em SIG no mundo acadêmico, nas empresas de software e entre profissionais liberais, como consequência do aumento da capacidade de processamento, da redução dos custos dos microcomputadores e do aumento da disponibilidade de bases de dados cartográficos digitais. Devido aos requisitos específicos para aplicações em transportes e à adoção de tecnologia de informação nessa área, pesquisadores aumentaram seus esforços para aprimorar a abordagem existente de SIG, de forma a capacitá-lo à aplicação em estudos de transportes, dando origem aos chamados SIG-T (Sistemas de Informações Geográficas para Transportes).

De acordo com Church (2002), seis fatores inter-relacionados se destacam no crescimento da utilização do SIG: 1) existe uma gama de softwares SIG disponibilizados a partir de vendedores comerciais e universidades; 2) aumento da capacidade dos computadores em armazenar e recuperar grandes quantidades de dados, em tempos e custos razoáveis; 3) impressoras estão mais sofisticadas e rápidas, produzindo saídas de alta resolução e qualidade; 4) uma maior disponibilidade de dados geográficos a partir de empresas privadas e agências governamentais, a custos acessíveis; 5) a expansão do uso do sensoriamento remoto, o que requer sistemas capazes de lidar com largas quantidades de dados; 6) o surgimento do GPS (Global Positioning System), que facilitou a coleta de dados espaciais, a custos relativamente baixos e alta precisão.

\subsection{Aplicações de SIG em problemas de localização de instalações}

Conforme Lorena et al. (2001), vários trabalhos vêm sendo desenvolvidos na área de logística, localização de instalações e roteirização de veículos usando um SIG, algumas vezes combinados com outras técnicas matemáticas, sejam aplicadas ao setor público ou privado. No caso do setor privado, o objetivo principal é a minimização de custos logísticos. Em indústrias, atacadistas, varejistas e distribuidores, por exemplo,

Quadro 1. Classificação de problemas de localização (OWEN; DASKIN, 1998).

\begin{tabular}{|c|l|}
\hline Problema & \multicolumn{1}{c|}{ Descrição } \\
\hline $\begin{array}{c}\text { Modelo das } \\
p \text {-medianas }\end{array}$ & $\begin{array}{l}\text { Localizar } p \text { instalações nos vértices de uma rede e alocar a demanda a estas instalações, de tal forma } \\
\text { a minimizar as distâncias percorridas. Se as instalações são não capacitadas e } p \text { é fixo, temos então o } \\
\text { problema das } p \text {-medianas, em que cada vértice é designado para sua instalação mais próxima. Se } p \text { é } \\
\text { uma variável de decisão e as instalações são capacitadas ou não capacitadas, isto define o Problema } \\
\text { de Localização de Instalações Capacitadas ou Não capacitadas, respectivamente. Estes modelos são } \\
\text { particularmente relevantes para o projeto de serviços logísticos e distribuição de cargas. }\end{array}$ \\
\hline $\begin{array}{c}\text { Cobertura de } \\
\text { conjuntos }\end{array}$ & $\begin{array}{l}\text { Baseia-se na distância ou tempo de viagem máximos aceitáveis, buscando a minimização do número } \\
\text { de facilidades necessárias para garantir certo nível de cobertura de clientes. Assume um conjunto finito } \\
\text { de localizações e geralmente está associado a um orçamento fixo. É muito utilizado na localização de } \\
\text { serviços públicos, tais como centros de saúde, agências de correio, bibliotecas ou escolas. }\end{array}$ \\
\hline centros & $\begin{array}{l}\text { É um problema minimax cujo objetivo é minimizar a máxima distância entre os pontos de demanda } \\
\text { e a facilidade mais próxima. Deseja-se cobrir toda a demanda procurando localizar certo número de } \\
\text { facilidades, desde que minimize a distância coberta. Quando a localização da facilidade está restrita } \\
\text { ao nó da rede, tem-se o problema de centro de vértice. Caso se permita a localização em qualquer } \\
\text { lugar da rede, o problema é de centro absoluto. São modelos principalmente aplicados a serviços de } \\
\text { emergência, tais como estação de bombeiros e de ambulâncias. }\end{array}$ \\
\hline
\end{tabular}


para se decidir o melhor local para instalar uma unidade, seja uma planta de produção, uma loja, um centro de distribuição ou armazenagem, deve-se sempre levar em consideração o posicionamento do mercado consumidor e de seus fornecedores, a disponibilidade de infraestrutura, de mão de obra e de vários outros fatores que afetam a produção.

Gu, Wang e Geng (2009) apresentam uma nova classe de problemas de localização e alocação de instalações por considerar a localização ótima de dois tipos de instalações, estáticas e de transporte, de forma a atender a um custo mínimo determinada região. Para exemplificar, considera-se a localização de hospitais como instalação estática e a localização de ambulâncias como instalações de transporte. A localização das instalações ditas de transporte é dependente da localização das instalações estáticas e da demanda. Os autores propuseram uma nova plataforma GIS combinada com um algoritmo heurístico customizado para resolver o problema, sendo os resultados disponibilizados em uma interface gráfica amigável, usando assim vários recursos do SIG no desenvolvimento e aplicação em modelos de localização. Biberacher (2008) desenvolveu um modelo baseado em SIG para a localização de sistemas de energia eólica, solar e hidráulica relacionada com as características temporais, de suprimento e de demanda mundiais, tendo por objetivo a localização de fontes de energia para suprir a demanda global do século XXI.

Outros exemplos de aplicação de SIG em estudos de localização podem ser vistos em: Carnasciali e Delazari (2007), que integrou o SIG ArcGIS e um sistema especialista para auxiliar a localização de agências bancárias; Arakaki e Lorena (2006), que desenvolveram uma heurística integrada ao SIG de localização-alocação para problemas de localização de máxima cobertura e de $p$-medianas; Zambon et al. (2005), que aplicaram análise de decisão multicritério na localização de usinas termoelétricas utilizando SIG-T; Pizzolato e Silva (1997), que fazem um estudo da localização atual e uma proposta de reposicionamento de escolas públicas em municípios brasileiros; Lima (2003), que estudou a localização de creches e postos de saúde em regiões urbanas utilizando os modelos de localização do SIG; Naruo (2003), que fez um estudo de localização de estações de tratamento de esgoto e aterros sanitários; Dobrusky (2003), que localiza centros de cross-docking para uma rede de produtos farmacêuticos; Silva (2004), que estuda a localização de terminais de consolidação para uma empresa de transporte de carga parcelada; Hamad (2006), que desenvolveu um modelo de localização de fábricas e/ou depósitos em escala global para corporações transnacionais.

Conforme Lorena et al. (2001), a capacidade de um SIG aumenta consideravelmente quando se faz o uso combinado com técnicas de Pesquisa Operacional. Church e Sorensen (1996) apontam que o uso de modelos de programação exata que utilizam o algoritmo branch and bound está limitado a encontrar uma solução global efetivamente ótima para problemas com no máximo 150 nós na rede. Um algoritmo de branch and bound é um método de busca em árvore com enumeração inteligente das soluções candidatas à solução ótima de um problema, efetuando sucessivas partições do espaço das soluções e cortando a árvore de busca pela consideração de limites calculados ao longo da enumeração. O cálculo dos limites para o valor da solução ótima é uma parte fundamental de um algoritmo branch and bound, pois são usados para limitar o crescimento da árvore. Segundo Beasley (1993), a utilização de técnicas mais robustas, como a relaxação lagrangeana com subgradiente de otimização, faz aumentar a capacidade de lidar com problemas de otimização mais complexos, da ordem de 800 a 900 nós na rede. Sendo assim, algoritmos exatos são utilizados apenas em soluções de problemas com um número restrito de variáveis e restrições, como no máximo 150 nós na rede, conforme Church e Sorensen (1996) propuseram em seu trabalho.

\section{Metodologia de pesquisa}

O modelo matemático desenvolvido é classificado como estático-determinístico, resolvido por uma variante do método das $p$-medianas, no qual o objetivo é encontrar a localização de $p$-facilidades tal que a distância total entre centros de demanda e oferta seja minimizada e, simultaneamente, alocam-se os fluxos entre as facilidades e os clientes. Foi proposta então uma interação entre o SIG e o modelo matemático externo baseado em Programação Linear Inteira Mista (PLIM), que se dará durante a entrada e saída de dados. Segundo Church e Sorensen (1996) e Vallim Filho (2004), a PLIM é o método matemático mais empregado para resolução de problemas de localização formulados segundo o método das $p$-medianas, conduzindo para a solução ótima do problema.

O objetivo principal é avaliar a qualidade da solução gerada pelo software SIG, em suas rotinas combinadas FL e TP, quando comparadas à solução ótima obtida no modelo PLIM. Mesmo que, numa hipótese pessimista, a qualidade da solução matemática obtida pelos modelos do SIG seja ruim, não se pode negar seu grande auxílio nas fases de obtenção de dados e de apresentação e análise de resultados, por meio de suas ferramentas para geração de gráficos e mapas temáticos, entre outros. De acordo com Church (2002), não é difícil exportar dados a partir do SIG, que servirão de entrada para outro modelo de localização, externo ao SIG, que irá resolver o problema proposto, e então importar os resultados 
de volta ao SIG, para gerar os resultados gráficos em forma de mapa. O modelo PLIM foi implementado usando o software de otimização LINGO ${ }^{\circledR}$, versão 7.0, com interface em planilha eletrônica MS Excel ${ }^{\circledR}$, detalhado nas equações:

Função Objetivo:

$$
\min f o=\sum_{i} \sum_{j} C_{i, j} * X_{i, j} * d_{j}
$$

Sujeito a:

$$
\begin{array}{lr}
\sum_{i} z_{i}=p & \\
X_{i, j} \leq z_{i} & \forall_{i, j} \\
\sum_{i} X_{i, j}=1 & \forall_{j} \\
\sum_{j} d_{j} * X_{i, j} \leq m_{i} * & z_{i} \forall_{i} \\
z_{i} \in(0,1) & \forall_{i} \\
X_{i, j} \in Z^{+} & \forall_{i, j}
\end{array}
$$

Em que:

$X_{i, j}$ :é a matriz solução. Indica a demanda relativa de $j$-atendida por $i$;

$C_{i, j}$ :matriz de custos, representada pelas distâncias mínimas entre os pontos $i$ e $j$;

$z_{i}$ :é um vetor de binários, que indica quais facilidades estão abertas. Se $z_{i}=1$, a facilidade $i$ está aberta. Caso contrário, se $z_{i}=0$, então a facilidade $i$ não está em operação;

$d_{i}$ :vetor que armazena as demandas dos clientes $j$; $m_{i}$ :parâmetro de entrada que define a capacidade máxima da facilidade $i$;

$p$ : parâmetro de entrada que especifica a quantidade de facilidades a serem abertas.

A Equação 1 representa a função objetivo do modelo, que visa minimizar o custo de transporte, em função das distâncias entre os pontos (conjunto de facilidades) e (conjunto de clientes), ponderado pela porcentagem da demanda atendida, assim como a função objetivo utilizada no SIG, para posterior comparação dos resultados gerados entre os dois modelos. Com relação às restrições, vale ressaltar que a Equação 2 é a restrição que indica a quantidade de facilidades a serem abertas, equivalente ao número $p$; Equação 3 representa a restrição de abertura de facilidade, ou seja, se a facilidade não está em operação $\left({ }_{i}\right)$, a alocação de demanda a esta facilidade deve ser nula; Equação 4 é a restrição de cobertura de demanda, na qual todos os clientes deverão ter o total de suas demandas atendidas; Equação 5 é a restrição de limite superior de capacidades das facilidades a serem abertas; Equação 6 torna o vetor de saída ${ }_{i}$ um vetor de binários; e Equação 7 torna a matriz solução ${ }_{i, j}$ uma matriz de inteiros.
A metodologia de pesquisa adotada no trabalho pode ser classificada como uma pesquisa científica de natureza aplicada, seguindo abordagem quantitativa, com objetivos exploratórios e utilizando-se da modelagem e simulação como procedimento técnico (BERTRAND; FRANSOO, 2002). Foi posta em prática em três simulações, segundo os modelos SIG e PLIM, envolvendo diferentes níveis de complexidade. De forma geral, o problema de localização-alocação abordará a minimização de custos de transportes em uma rede logística, em que os centros de oferta (ou de distribuição) deverão atender totalmente às demandas dos clientes, estando ou não sujeitos à restrição de limite superior de capacidade das instalações. Entende-se aqui por custos de transportes apenas as distâncias percorridas entre os pontos de origem e destino (ou demanda e oferta), sendo essas representadas na Equação 1 e na matriz $C_{i, j}$. Não são consideradas outras variáveis relevantes para o cálculo dos custos efetivos de transportes de modo mais amplo, como combustível, veículos etc., mas essa simplificação não representa limitação às análises, tendo em vista que as mesmas condições são mantidas em todos os cenários. Adicionalmente, entende-se aqui que há uma relação direta entre as distâncias percorridas e os custos de transportes: quanto menor for a distância a ser percorrida entre $o$ ponto de origem e o ponto de destino, menor será o custo de transporte e/ou deslocamento. Para suportar os cálculos dos modelos, foi utilizado um computador com processador AMD Sempron 2.600, de 1,83 GHz e 512 MB de memória RAM, operando sob o sistema operacional Microsoft Windows XP Professional.

\section{Simulações}

\subsection{Simulação I - localização de fábricas}

O problema proposto para esta simulação é realizar a localização e respectiva alocação entre pontos de oferta (fábricas) e de demanda (clientes) no Estado de São Paulo, englobando 18 de seus principais municípios (Figura 1). Para se localizar os pontos de oferta, a escolha se dará em um espaço discreto, que incluirá todos os 18 municípios como candidatos à abertura de instalações, para os dois modelos, SIG e PLIM.

Começando pelo modelo SIG, programou-se inicialmente a rotina FL para localizar uma única fábrica, de tal forma que esta suprisse a demanda total dos clientes (constituindo o Cenário 1 de simulação). Novos cenários de simulação são propostos à medida que se abre uma nova unidade, até atingir o total de instalações, tal que o custo médio de transporte seja inferior a $100 \mathrm{~km}$, caracterizando um problema de cobertura, situação esta obtida no Cenário 4 de simulação. A descrição dos cenários simulados está 


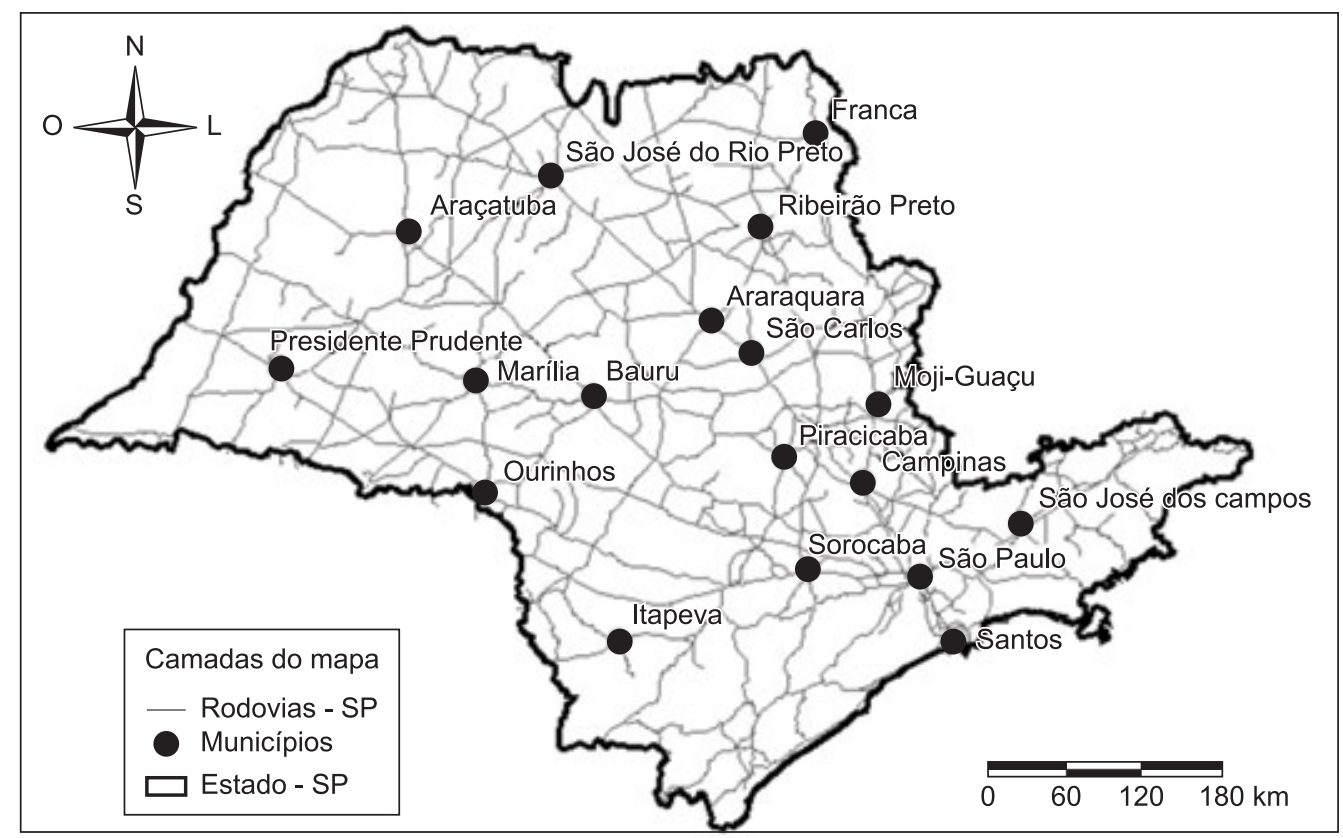

Figura 1. Representação da região para a Simulação I.

disposta no Quadro 2. É importante destacar que, nos cenários que envolvem a restrição de capacidade, nessa e em todas as outras simulações, a capacidade dos centros de oferta foi considerada como sendo a demanda total dos clientes dividida igualmente entre o número de centros de oferta.

A função objetivo habilitada em todos os cenários alternativos foi a de minimizar o custo médio de serviço de transporte. Os resultados numéricos dos cenários gerados pelo modelo SIG, para as rotinas Facility Location (FL) e Transportation Problem (TP), podem ser obtidas na Tabela 1. A Figura 2 ilustra as localizações das fábricas em cada cenário, além das alocações entre fábricas/clientes (por cores) e do total de demanda suprida por cada fábrica (valores indicados entre parêntesis nas legendas).

Pela análise da Tabela 1, pode-se perceber que os valores de Custo Total de serviço de transporte diminuem à medida que se aumenta o número de fábricas, uma vez que assim os clientes ficam mais próximos, reduzindo os custos de transporte. Analisando as soluções geradas pela rotina TP, que realocou as demandas conforme as capacidades máximas das fábricas, permitindo sua fragmentação (clientes/cidades podem ser atendidos por mais de uma fábrica) percebe-se um aumento no valor do Custo Total (nos Cenários 2, 3 e 4), quando cada cenário é comparado com a respectiva solução gerada pela rotina FL. Este aumento é consequência dos limites de capacidade máxima de oferta imposta às instalações pela rotina TP, que, uma vez atingidos, não poderá mais alocar demanda àquela instalação.
O tempo de processamento computacional foi menor que 1 segundo em todas as situações.

Para se estabelecer uma comparação entre os modelos SIG e PLIM, os mesmos cenários utilizados no modelo SIG (Quadro 2) foram simulados no modelo PLIM. O modelo PLIM pode também resolver o problema sem considerar a capacidade das instalações, que foi denominado de rotina Não Capacitada (NC), funcionando exatamente como a rotina FL do SIG. Quando considerou essas capacidades, o modelo foi denominado de rotina Capacitada (C), realizando a localização e alocação das instalações aos seus clientes e verificando os limites de capacidade máxima destas instalações de forma simultânea, ao contrário do SIG. Assim, para efeito de comparação, a rotina C/PLIM corresponde à rotina $\mathrm{TP} / \mathrm{SIG}$, ressaltando que a saída $\mathrm{TP}$ do SIG na verdade significa o uso combinado das rotinas FL e TP. Os resultados quantitativos do modelo PLIM são apresentados na Tabela 2.

A Figura 3 apresenta os resultados espaciais apenas para os Cenários 3 e 4, nos quais as soluções de localização das fábricas propostas pelas rotinas $\mathrm{NC} \mathrm{e}$ $\mathrm{C}$ foram diferentes. Comparando as soluções geradas pelos modelos SIG e PLIM, nota-se que, em um primeiro momento, os dois modelos comportam-se de forma semelhante. As soluções produzidas pela FL/SIG foram iguais às geradas pela NC/PLIM, em todos os cenários. Este aspecto pode ser visto comparando-se os valores da variável Custo Total, disponíveis na Tabela 3, para as rotinas FL/SIG e NC/PLIM. 
Quadro 2. Definição dos cenários para a Simulação I.

\begin{tabular}{|l|l|}
\hline Cenário 1 & Abertura de 1 instalação para suprir a demanda total. \\
\hline Cenário 2 & Abertura de 1 nova unidade, perante a existência da fábrica localizada no Cenário 1. \\
\hline Cenário 3 & Abertura de 2 novas unidades, perante a existência da fábrica localizada no Cenário 1. \\
\hline Cenário 4 & Abertura de 3 novas unidades, perante a existência da fábrica localizada no Cenário 1. \\
\hline
\end{tabular}

Tabela 1. Soluções geradas no modelo SIG para a Simulação I.

\begin{tabular}{cccccccccc}
\hline Cenário & \multicolumn{3}{c}{ Características } & & \multicolumn{2}{c}{ Facility Location $(\mathbf{F L})$} & & \multicolumn{2}{c}{ Transportation Problem $(\mathrm{TP})$} \\
\cline { 2 - 3 } & $\begin{array}{c}\text { Fábrica } \\
\text { existente }\end{array}$ & $\begin{array}{c}\text { Novas } \\
\text { fábricas }\end{array}$ & $\begin{array}{c}\text { Total } \\
\text { fábricas }\end{array}$ & $\begin{array}{c}\text { Custo médio } \\
(\mathbf{k m})\end{array}$ & $\begin{array}{c}\text { Custo total } \\
(\mathbf{k m})\end{array}$ & & $\begin{array}{c}\text { Capacidade } \\
\text { máxima }\end{array}$ & $\begin{array}{c}\text { Custo total } \\
(\mathbf{k m})\end{array}$ \\
\hline $\mathbf{1}$ & 0 & 1 & 1 & & 209,3 & $\mathbf{3 4 . 9 5 4}$ & & 167 & $\mathbf{3 4 . 9 5 4}$ \\
$\mathbf{2}$ & 1 & 1 & 2 & & 142,1 & $\mathbf{2 3 . 7 4 0}$ & & 84 & $\mathbf{2 4 . 0 3 4}$ \\
$\mathbf{3}$ & 1 & 2 & 3 & & 117,4 & $\mathbf{1 9 . 6 0 9}$ & & 56 & $\mathbf{2 2 . 1 7 7}$ \\
$\mathbf{4}$ & 1 & 3 & 4 & & 93,3 & $\mathbf{1 5 . 5 9 1}$ & & 42 & $\mathbf{1 6 . 9 1 3}$ \\
\hline
\end{tabular}

Cenário 1

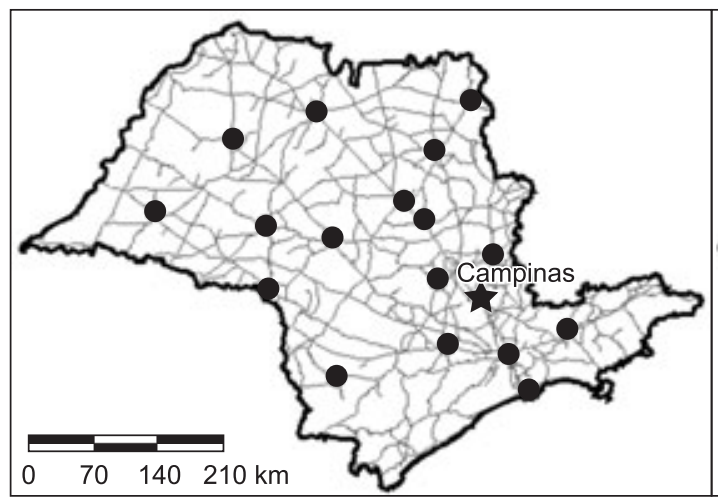

Fábricas instaladas

خ Campinas (167)
Cenário 2

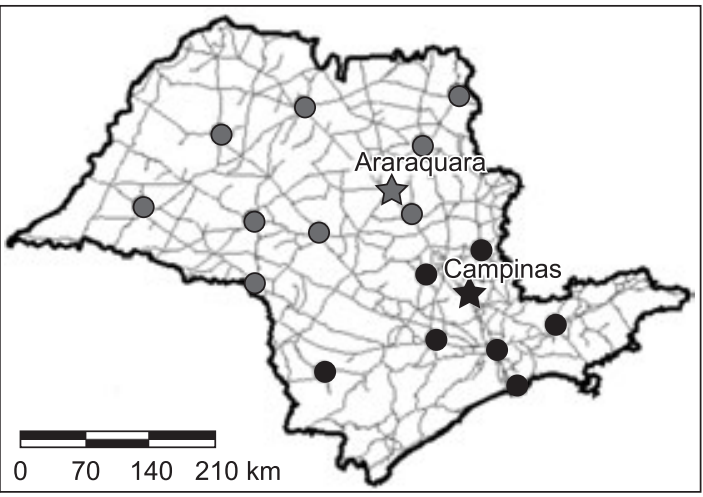

Fábricas instaladas

Campinas (91) 饶 Araraquara (76)

Cenário 3

Cenário 4

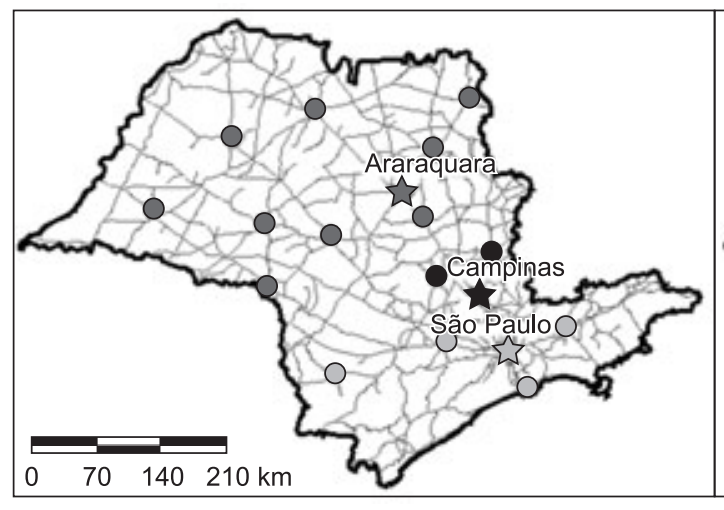

Fábricas instaladas

Campinas (30) 药 Araraquara (76) 饮 São Paulo (61)

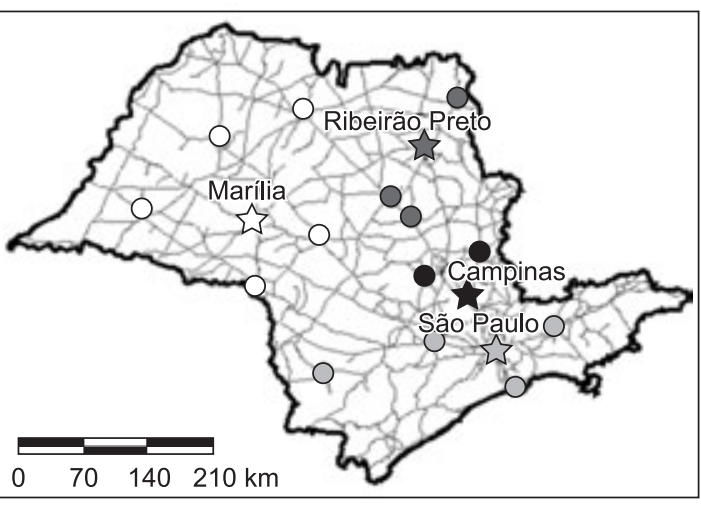

Fábricas instaladas

Campinas (30) 㨱 Ribeirão Preto (34) 饮 São Paulo (61) 论 Marília (42)

Figura 2. Soluções geradas pela rotina Facility Location para a Simulação I. 
Tabela 2. Soluções geradas no modelo PLIM para a Simulação I.

\begin{tabular}{ccccccccc}
\hline Cenário & \multicolumn{2}{c}{ Características } & & \multicolumn{2}{c}{ Não capacitada (NC) } & & \multicolumn{2}{c}{ Capacitada (C) } \\
\cline { 2 - 3 } & $\begin{array}{c}\text { Fábrica } \\
\text { existente }\end{array}$ & $\begin{array}{c}\text { Novas } \\
\text { fábricas }\end{array}$ & & $\begin{array}{c}\text { Tempo } \\
\text { computacional }\end{array}$ & $\begin{array}{c}\text { Custo total } \\
(\mathbf{k m})\end{array}$ & & $\begin{array}{c}\text { Tempo } \\
\text { computacional }\end{array}$ & $\begin{array}{c}\text { Custo total } \\
(\mathbf{k m})\end{array}$ \\
\hline $\mathbf{1}$ & 0 & 1 & & $00: 00: 01$ & $\mathbf{3 4 . 9 5 4}$ & & $00: 00: 01$ & $\mathbf{3 4 . 9 5 4}$ \\
$\mathbf{2}$ & 1 & 1 & & $00: 00: 01$ & $\mathbf{2 3 . 7 4 0}$ & & $00: 00: 01$ & $\mathbf{2 4 . 0 3 4}$ \\
$\mathbf{3}$ & 1 & 2 & & $00: 00: 01$ & $\mathbf{1 9 . 6 0 9}$ & & $00: 00: 01$ & $\mathbf{2 0 . 5 9 7}$ \\
$\mathbf{4}$ & 1 & 3 & & $00: 00: 01$ & $\mathbf{1 5 . 5 9 1}$ & & $00: 00: 01$ & $\mathbf{1 6 . 6 6 0}$ \\
\hline
\end{tabular}
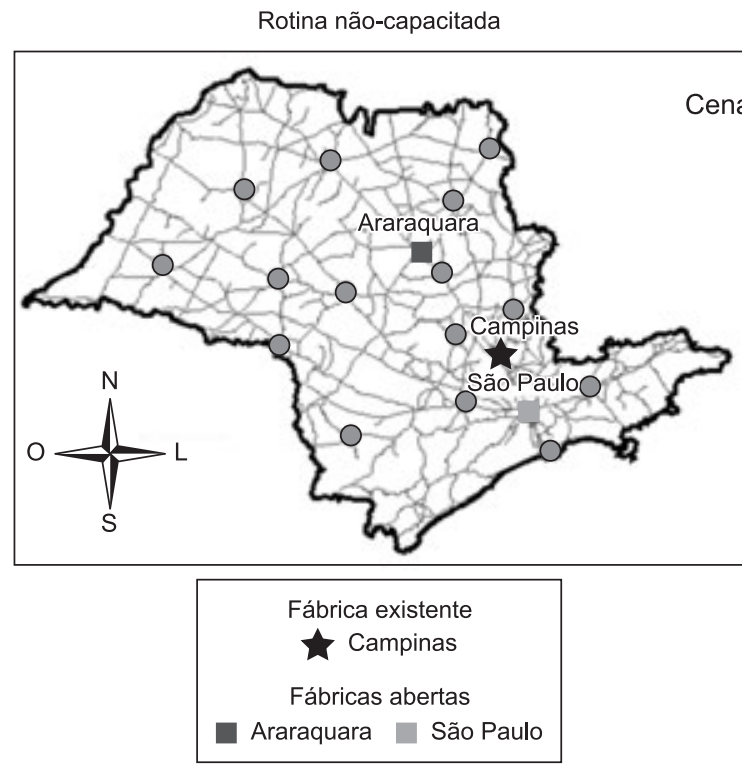

Rotina capacitada
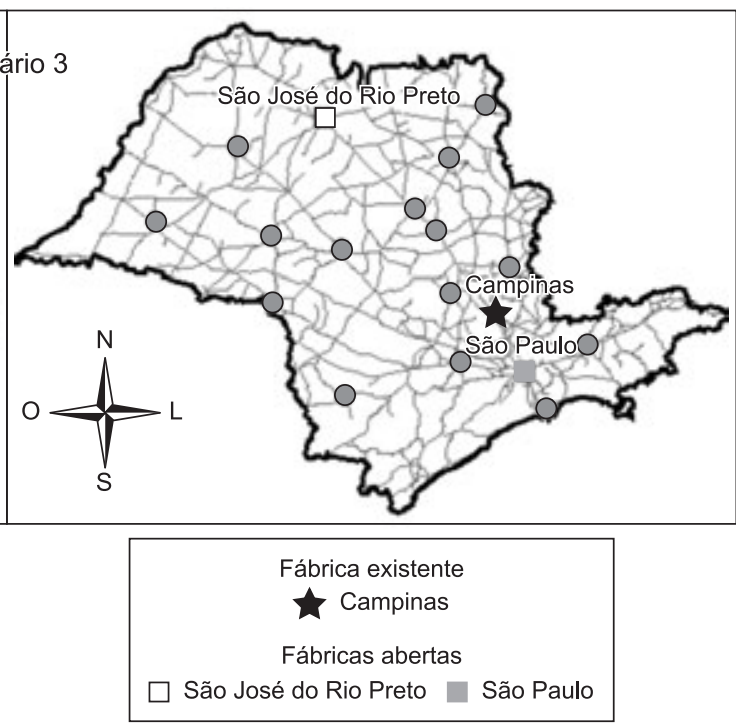

Rotina não-capacitada Rotina capacitada
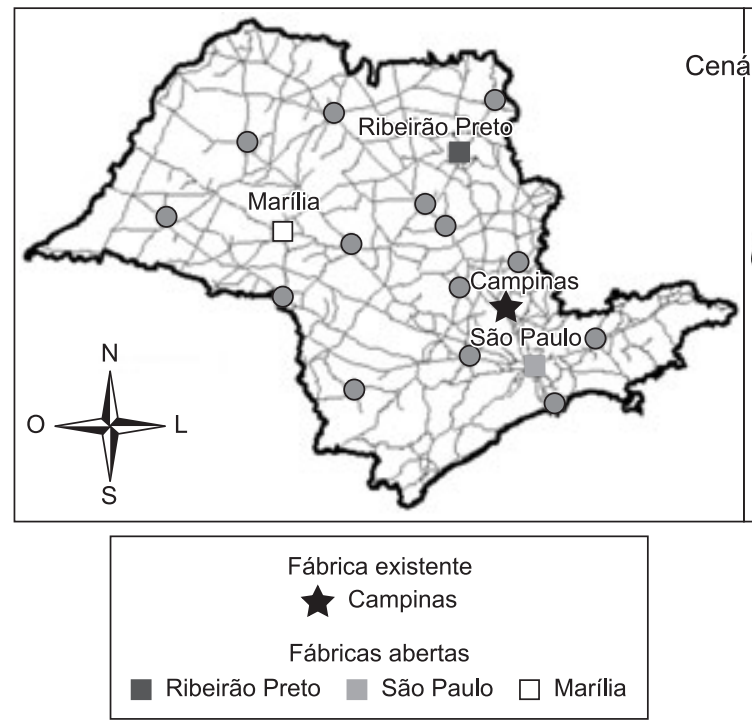
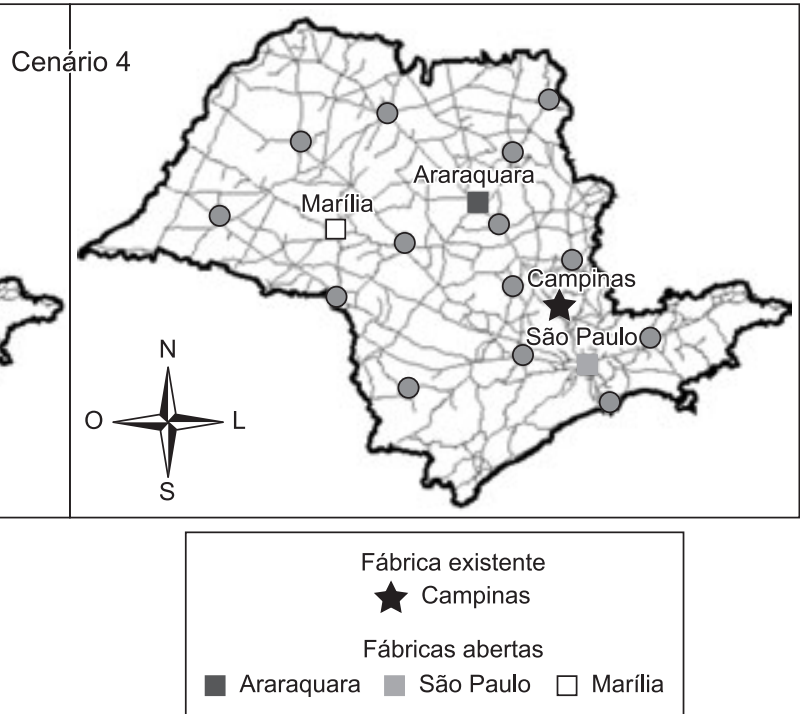

Figura 3. Soluções geradas pelo modelo PLIM para os Cenários 3 e 4 da Simulação I.

Partindo para a comparação entre as rotinas TP/SIG (que não permite alterar a localização das fábricas obtidas pela rotina FL) e C/PLIM, percebe-se pelos mapas apresentados nas Figuras 2 e 3, que as soluções de localização dos Cenários 3 e 4 foram diferentes entre os dois modelos. Estes diferentes locais de instalação das fábricas impactam em maiores ou menores custos de transporte, cuja comparação percentual, em termos 
Tabela 3. Comparação das soluções dos modelos SIG e PLIM para Simulação I.

\begin{tabular}{|c|c|c|c|c|c|c|}
\hline \multirow[t]{3}{*}{ Cenário } & \multicolumn{2}{|c|}{ Modelo SIG } & \multicolumn{2}{|c|}{ Modelo PLIM } & \multicolumn{2}{|c|}{ Variação (\%) } \\
\hline & FL & TP & $\mathrm{NC}$ & C & FL vs. NC & TP vs. C \\
\hline & $\begin{array}{l}\text { Custo total } \\
(\mathbf{k m})\end{array}$ & $\begin{array}{l}\text { Custo total } \\
(\mathbf{k m})\end{array}$ & $\begin{array}{l}\text { Custo total } \\
(\mathbf{k m})\end{array}$ & $\begin{array}{l}\text { Custo total } \\
(\mathbf{k m})\end{array}$ & $\begin{array}{l}\text { Custo total } \\
\text { (km) }\end{array}$ & $\begin{array}{l}\text { Custo total } \\
(\mathbf{k m})\end{array}$ \\
\hline 1 & 34.954 & 34.954 & 34.954 & 34.954 & $\mathbf{0 , 0 \%}$ & $\mathbf{0 , 0 \%}$ \\
\hline 2 & 23.740 & 24.034 & 23.740 & 24.034 & $0,0 \%$ & $0,0 \%$ \\
\hline 3 & 19.609 & 22.177 & 19.609 & 20.597 & $0,0 \%$ & $7,7 \%$ \\
\hline 4 & 15.591 & 16.913 & 15.591 & 16.660 & $0,0 \%$ & $1,5 \%$ \\
\hline
\end{tabular}

da redução obtida pelo modelo PLIM comparada ao SIG, pode ser observada na Tabela 3. Percebe-se que houve variações entre os valores de Custo Total dos modelos SIG e PLIM, nos Cenários 3 e 4 de simulação, que reduziu os custos de deslocamentos em 7,7 e 1,5\%, respectivamente, em função das distintas localizações para abertura de instalações, e consequentemente diferentes alocações.

Quanto ao tempo de processamento, em ambos os modelos, o tempo ficou na ordem de 1 segundo, ou seja, não constituiu empecilho para a geração das soluções no modelo exato PLIM quando comparado ao modelo heurístico do SIG. Porém, o problema abordado nesta simulação é de pequeno porte, o que foi a principal motivação para se testar o modelo PLIM em problemas de maior porte, como será visto nas Simulações II e III.

\subsection{Simulação II - localização de CDs atacadistas}

Na Simulação II, o objetivo é localizar centros de distribuição (CD), para uma empresa atacadista do sul de Minas Gerais. A empresa possui um único CD localizado na cidade de Poços de Caldas, MG. $\mathrm{O}$ atacadista possui um total de aproximadamente 12.000 clientes, sendo $30 \%$ deles localizados no sul de Minas Gerais e 70\% distribuídos no interior de São Paulo, concentrados no Vale do Paraíba e regiões de Campinas e Ribeirão Preto. Para fins de simplificação do problema, todos os clientes pertencentes ao mesmo município foram agrupados e tiveram suas demandas somadas em um único ponto, de modo que o problema foi tratado em escala estadual: os pontos de demanda eram municípios interligados por rodovias. Sendo assim, gerou-se um total de 311 municípios-clientes, com suas respectivas localizações geográficas e demanda total. O número de municípios candidatos a terem um $\mathrm{CD}$ foi restrito a 150 para os modelos SIG e PLIM, escolhidos entre aqueles municípios-clientes que possuem os maiores valores de demanda ( $89 \%$ da demanda total). Essa foi a primeira restrição significativa do modelo PLIM. Apesar do Lingo não impor limites quanto ao número de variáveis e restrições do problema (apenas o tempo de processamento que se eleva de forma exponencial), a planilha Excel, em interface com o Lingo, tem um limite máximo do número de colunas (256) para armazenar a matriz de custos (distâncias) entre os municípios-clientes e candidatos à localização de CDs.

O critério para geração dos cenários, apresentados no Quadro 3, foram os mesmos da Simulação I. A Tabela 4 mostra seus resultados numéricos. O Quadro 4 identifica os municípios-clientes, selecionados no modelo SIG e posteriormente no modelo PLIM. Para fins ilustrativos, é apresentada na Figura 4 a solução gráfica para o Cenário 4 da rotina FL/SIG, na qual também pode-se observar a localização do CD existente e todos os 150 municípios clientes/candidatos. Pela Tabela 4, percebe-se que o custo total mínimo de transporte com o atual CD (Cenário 1) seria de $820 \times 10^{6} \mathrm{~km}$. Ao se abrir um novo CD no modelo TP/SIG (Cenário 2 ), o atacadista poderia reduzir seus custos de transporte em $38,3 \%$ se comparado ao Cenário 1.

A Tabela 5 apresenta os resultados do modelo PLIM para os mesmos cenários. Além da variável Custo Total, a Tabela 5 apresenta também o tempo de processamento computacional, que aumenta com o número de CDs a serem localizados. Em todos os cenários que incluíam a abertura de novos CDs (2, 3 e 4$)$, as rotinas C/PLIM e NC/PLIM indicaram cidades diferentes para a abertura desses novos CDs. A comparação entre os modelos SIG e PLIM é apresentada na Tabela 6, de modo análogo à Tabela 3.

Uma vez mais, percebe-se que não houve variação nas soluções obtidas via rotinas FL/SIG e NC/PLIM. Isso já é uma evidência clara da qualidade da solução heurística do SIG em seu modelo não capacitado. Nos modelos capacitados, a rotina C/PLIM teve resultados 22,6 e 13,8\% menores do que os obtidos via TP/SIG, para os Cenários 3 e 4, respectivamente. A Figura 5 ilustra as diferentes localizações obtidas pelos modelos SIG e PLIM para o Cenário 3. Com a evidência de que a diferença entre as soluções dos modelos capacitados aumentava com o tamanho do problema, optou-se por simular um problema de porte ainda maior para confirmar essa hipótese, que será apresentado a seguir. 
Quadro 3. Definição dos cenários da Simulação II.

\begin{tabular}{|l|l|}
\hline Cenário 1 & Alocação dos municípios-clientes ao CD existente em Poços de Caldas. \\
\hline Cenário 2 & Abertura de 1 novo CD, perante a existência do CD em Poços de Caldas. \\
\hline Cenário 3 & Abertura de 2 novos CDs, perante a existência do CD em Poços de Caldas. \\
\hline Cenário 4 & Abertura de 3 novos CDs, perante a existência do CD em Poços de Caldas. \\
\hline
\end{tabular}

Quadro 4. Identificação dos municípios-clientes para a Simulação II.

\begin{tabular}{|c|c|c|c|}
\hline Letra & Município-Cliente & Letra & Município-Cliente \\
\hline A & Poços de Caldas & E & Araraquara \\
\hline B & Limeira & F & Jundiaí \\
\hline C & Pindamonhangaba & G & Rio Claro \\
\hline D & Campinas & H & São Carlos \\
\hline
\end{tabular}

Tabela 4. Soluções geradas no modelo SIG para Simulação II.

\begin{tabular}{|c|c|c|c|c|c|}
\hline \multicolumn{6}{|c|}{ Modelo SIG } \\
\hline & \multicolumn{3}{|c|}{ Facility Location (FL) } & \multicolumn{2}{|c|}{ Transportation Problem (TP) } \\
\hline & $\begin{array}{c}\text { CDs } \\
\text { abertos }\end{array}$ & $\begin{array}{c}\text { Custo médio } \\
(\mathbf{k m})\end{array}$ & $\begin{array}{c}\text { Custo total } \\
\left(10^{6} \mathrm{~km}\right)\end{array}$ & $\begin{array}{c}\text { Capacidades } \\
(\mathrm{kg})\end{array}$ & $\begin{array}{c}\text { Custo total } \\
\left(10^{6} \mathrm{~km}\right)\end{array}$ \\
\hline Cenário 1 & $\mathbf{A}$ & 212 & 820 & 3.861 .936 & 820 \\
\hline Cenário 2 & $\mathbf{A}, \mathbf{B}$ & 121 & 461 & 1.930 .968 & 506 \\
\hline Cenário 3 & $\mathrm{~A}, \mathrm{~B}, \mathrm{C}$ & 101 & 383 & 1.287.312 & 503 \\
\hline Cenário 4 & $\mathbf{A}, \mathbf{C}, \mathrm{D}, \mathbf{E}$ & 83 & 315 & 965.484 & 402 \\
\hline
\end{tabular}

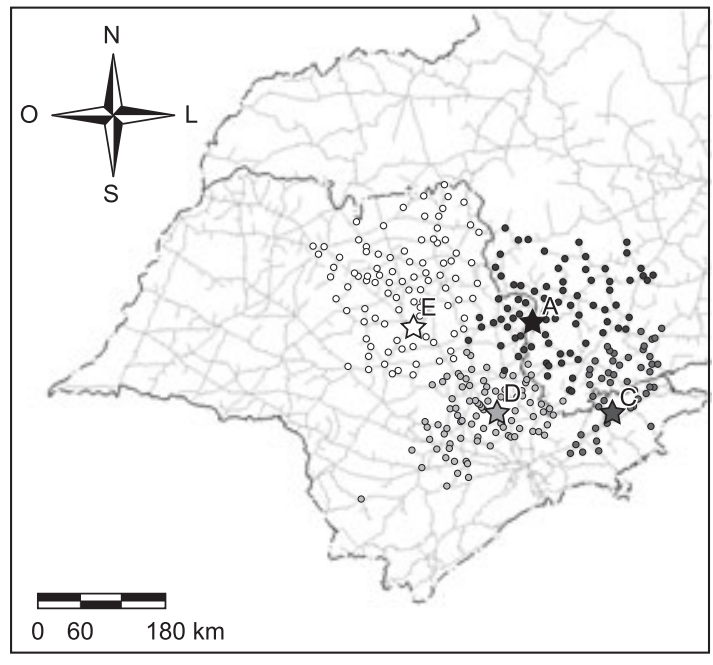

\begin{tabular}{|c|c|}
\hline \multicolumn{2}{|c|}{ Cenário 4 - CD's instalados } \\
\hline A (Poços de Caldas) & C (Pindamonhangaba) \\
\hline$\hat{D}$ (Campinas) & $己 E$ (Araraquara) \\
\hline
\end{tabular}

Figura 4. Solução gerada pela rotina FL/SIG para o Cenário 4 da Simulação II.

\subsection{Simulação III - localização de creches}

Esta simulação teve por base a localização de creches municipais e respectiva alocação de demanda, que são as crianças na faixa etária de 0 a 3 anos de idade. Foram utilizados os dados obtidos junto à
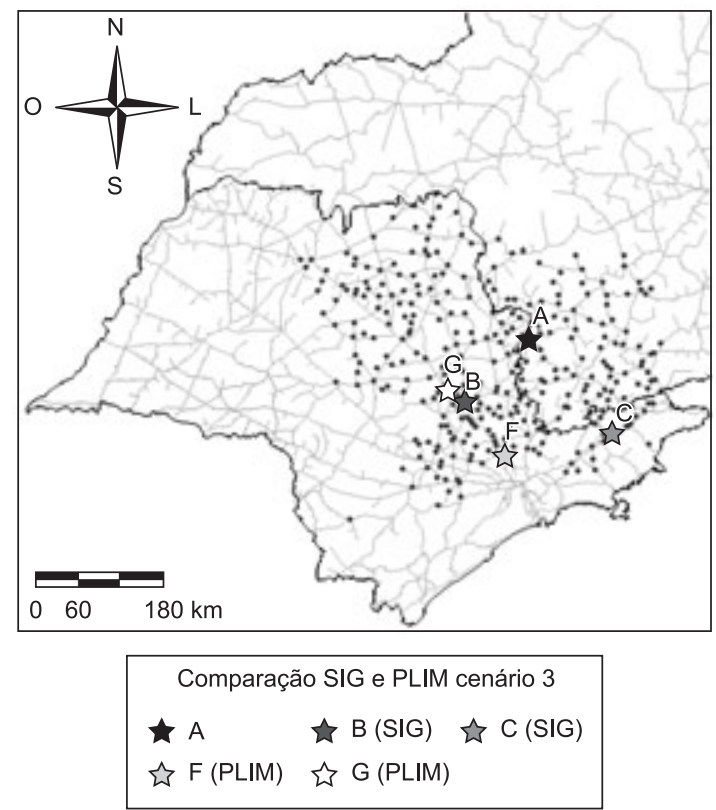

Figura 5. Distintas soluções dos modelos SIG e PLIM para o Cenário 3 da Simulação II.

Secretaria Municipal de Educação, georreferenciados em arquivo SIG com a rede viária da cidade. Estes dados correspondem basicamente ao endereço e à escola que frequentava cada um dos alunos da rede municipal de ensino público matriculados em creches, 
que somaram um total de 1.014 alunos, distribuídos em 10 creches existentes (dados do ano 2000).

$\mathrm{O}$ primeiro passo é a avaliação da localização e alocação real de alunos e creches. Para tanto, foram utilizados mapas temáticos do SIG, nos quais os alunos que frequentam uma mesma creche são identificados por uma mesma cor. A má distribuição espacial é facilmente identificada numa análise visual da Figura 6, nas quais as creches aparecem identificadas por um único símbolo, utilizando-se as letras de A a J para diferenciá-las. Na legenda do mapa, a cada creche está associado o número de alunos matriculados. A partir das informações obtidas na análise da situação real, diferentes cenários de localização e alocação entre creches e alunos foram propostos, que buscavam a maior concentração de alunos residindo próximo à creche que a frequentam. A descrição da situação real e dos cenários alternativos simulados é apresentada no Quadro 5.

Para o Cenário 1, os limites de capacidade impostos a cada uma das creches para a rotina TP foi estabelecido como sendo o número de alunos realmente matriculados na creche específica à época de coleta e análise dos dados, desconsiderando-se, por simplificação, se há falta ou excesso de vagas, pois o objetivo é somente a comparação dos modelos SIG e PLIM. Assim, foram mantidos os mesmos parâmetros nos dois modelos. Para os Cenário 2 e 3, nos quais foi proposta a abertura de novas creches, a capacidade das novas unidades foi estabelecida como sendo $10 \%$ da demanda total de alunos (101, de 1.014 alunos matriculados), reduzindo-se na mesma porcentagem a capacidade de cada creche existente. No Cenário 4, a capacidade de oferta da creche fechada foi realocada para a nova unidade aberta pelo modelo. Optou-se por escolher um número relativamente pequeno de candidatos à localização, a partir da localização de pontos equidistantes $(0,7 \mathrm{~km})$, que cobrissem toda a cidade, somando um total de 120 pontos. Somadas às 10 creches existentes, totalizam-se 130 candidatos, conjunto que foi o utilizado nos dois modelos (SIG e PLIM). Uma vez mais, a capacidade de processamento do modelo exato PLIM foi o limitante para o número de candidatos.

Os resultados do modelo SIG são apresentados nas Tabelas 7 (Cenários 1 e 2) e 8 (Cenários 3 e 4). Baseado nos valores custos médio, máximo e total, percebe-se que todos os cenários simulados

Tabela 5. Soluções geradas no modelo PLIM para Simulação II.

\begin{tabular}{|c|c|c|c|c|c|c|}
\hline \multicolumn{7}{|c|}{ Modelo PLIM } \\
\hline & \multicolumn{3}{|c|}{ Não Capacitada (NC) } & \multicolumn{3}{|c|}{ Capacitada $(\mathrm{C})$} \\
\hline & $\begin{array}{c}\text { CDs } \\
\text { abertos }\end{array}$ & $\begin{array}{c}\text { Tempo de } \\
\text { processo }\end{array}$ & $\begin{array}{c}\text { Custo total } \\
\left(10^{6} \mathrm{~km}\right)\end{array}$ & $\begin{array}{c}\text { CDs } \\
\text { abertos }\end{array}$ & $\begin{array}{c}\text { Tempo de } \\
\text { processo }\end{array}$ & $\begin{array}{c}\text { Custo total } \\
\left(10^{6} \mathrm{~km}\right)\end{array}$ \\
\hline Cenário 1 & A & 00h 00min 01seg & 820 & $\mathbf{A}$ & 00h 00min 01seg & 820 \\
\hline Cenário 2 & $\mathbf{A}, \mathbf{B}$ & 00h 00min 58seg & 461 & $\mathbf{A}, \mathbf{D}$ & $00 \mathrm{~h} 01 \mathrm{~min} 15 \mathrm{seg}$ & 500 \\
\hline Cenário 3 & $\mathrm{~A}, \mathbf{B}, \mathbf{C}$ & 00h $15 \mathrm{~min} 38 \mathrm{seg}$ & 383 & $\mathbf{A}, \mathbf{F}, \mathbf{G}$ & 00h $33 \mathrm{~min} 57 \mathrm{seg}$ & 410 \\
\hline Cenário 4 & $\mathbf{A}, \mathbf{C}, \mathbf{D}, \mathbf{E}$ & $01 \mathrm{~h} 44 \mathrm{~min} 10 \mathrm{seg}$ & 315 & $\mathbf{A}, \mathbf{B}, \mathbf{E}, \mathbf{F}$ & $01 \mathrm{~h} 06 \mathrm{~min} 05 \mathrm{seg}$ & 353 \\
\hline
\end{tabular}

Tabela 6. Comparação das soluções dos modelos SIG e PLIM para a Simulação II.

\begin{tabular}{|c|c|c|c|c|c|c|}
\hline & \multicolumn{2}{|c|}{ Modelo SIG } & \multicolumn{2}{|c|}{ Modelo PLIM } & \multicolumn{2}{|c|}{ Variação (\%) } \\
\hline & FL & TP & $\mathrm{NC}$ & $\mathrm{C}$ & FL vs. NC & TP vs. C \\
\hline & $\begin{array}{c}\text { Custo total } \\
\left(10^{6} \mathrm{~km}\right)\end{array}$ & $\begin{array}{c}\text { Custo total } \\
\left(10^{6} \mathrm{~km}\right)\end{array}$ & $\begin{array}{c}\text { Custo total } \\
\left(10^{6} \mathrm{~km}\right)\end{array}$ & $\begin{array}{c}\text { Custo total } \\
\left(10^{6} \mathrm{~km}\right)\end{array}$ & $\begin{array}{c}\text { Custo total } \\
\left(10^{6} \mathrm{~km}\right)\end{array}$ & $\begin{array}{c}\text { Custo total } \\
\left(10^{6} \mathrm{~km}\right)\end{array}$ \\
\hline Cenário 1 & 820 & 820 & 820 & 820 & $\mathbf{0 , 0 \%}$ & $\mathbf{0 , 0 \%}$ \\
\hline Cenário 2 & 461 & 506 & 461 & 500 & $0,0 \%$ & $1,4 \%$ \\
\hline Cenário 3 & 383 & 503 & 383 & 410 & $0,0 \%$ & $22,6 \%$ \\
\hline Cenário 4 & 315 & 402 & 315 & 353 & $0,0 \%$ & $13,8 \%$ \\
\hline
\end{tabular}

Quadro 5. Descrição dos cenários na Simulação III.

\begin{tabular}{|c|c|}
\hline Real & Localizações e alocações reais entre alunos e creches. \\
\hline Cenário 1 & Realocação dos alunos às 10 creches existentes. \\
\hline Cenário 2 & 10 creches existentes, abertura de 1 nova unidade. \\
\hline Cenário 3 & 10 creches existentes, abertura de 2 novas unidades. \\
\hline Cenário 4 & Fechamento de 1 das 10 creches existentes e a abertura de 1 nova unidade. \\
\hline
\end{tabular}



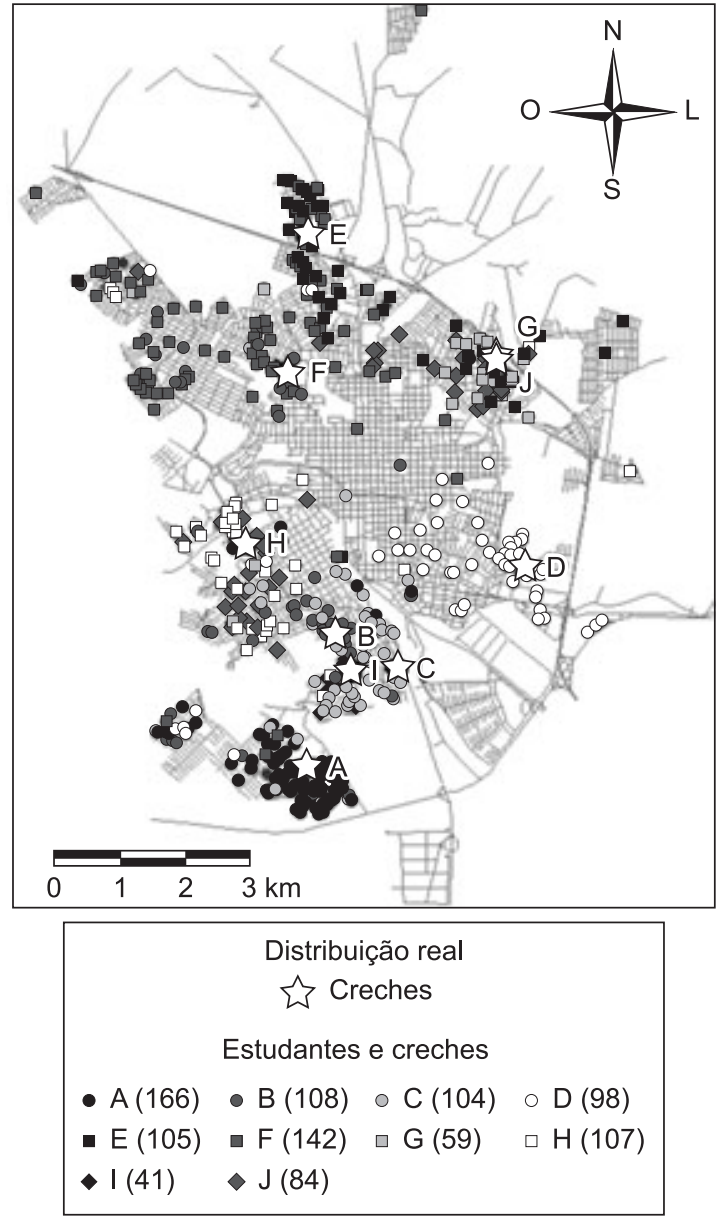

Figura 6. Distribuição real das creches e respectivos alunos para a Simulação III. apresentaram resultados melhores que a situação Real, com reduções que chegaram à ordem de $60 \%$. A simples realocação dos alunos no modelo existente (Cenário 1) levaria a reduções de 50\%. A alocação dos alunos às suas respectivas creches pode ser visualizada nos mapas temáticos da Figura 7, com os alunos agora bem menos dispersos. Os resultados obtidos pelo modelo PLIM são apresentados nas Tabelas 9 e 10. Os resultados são bastante semelhantes aos do modelo SIG, em termos quantitativos, com reduções significativas dos custos de deslocamento em relação à situação real. No entanto, a constatação mais significativa é que nos Cenários 2, 3 e 4 as rotinas $\mathrm{NC}$ e $\mathrm{C}$ do modelo PLIM geraram distintas localizações dentro de um mesmo cenário, ou seja, quando a restrição de limite máximo de capacidade é imposta ao modelo, as soluções de localização das creches se alteram, e consequentemente a alocação dos alunos. Por exemplo, no Cenário 2, no modelo NC a creche a ser aberta seria a $\mathrm{K}$, e no modelo $\mathrm{C}$ seria a M. Os tempos de processamento computacional, apresentados na Tabela 11, chegou a quase 2 horas no Cenário 3 capacitado.

A análise comparativa entre os modelos SIG e PLIM é apresentada na Tabela 12. Em todos os cenários, os dois modelos chegaram aos mesmos resultados para as rotinas não capacitadas. Porém, analisando as soluções das rotinas capacitadas, percebe-se que a rotina C/PLIM chegou a melhores soluções do que a TP/SIG, nos Cenários 2, 3 e 4, com diferenças de até 37\% (Cenário 4). Quanto aos locais escolhidos, o modelo NC/PLIM localizou as creches nos mesmos locais que o modelo FL/SIG (as mesmas da Figura 7,

Tabela 7. Resultados dos Cenários 1 e 2 para o modelo SIG para a Simulação III.

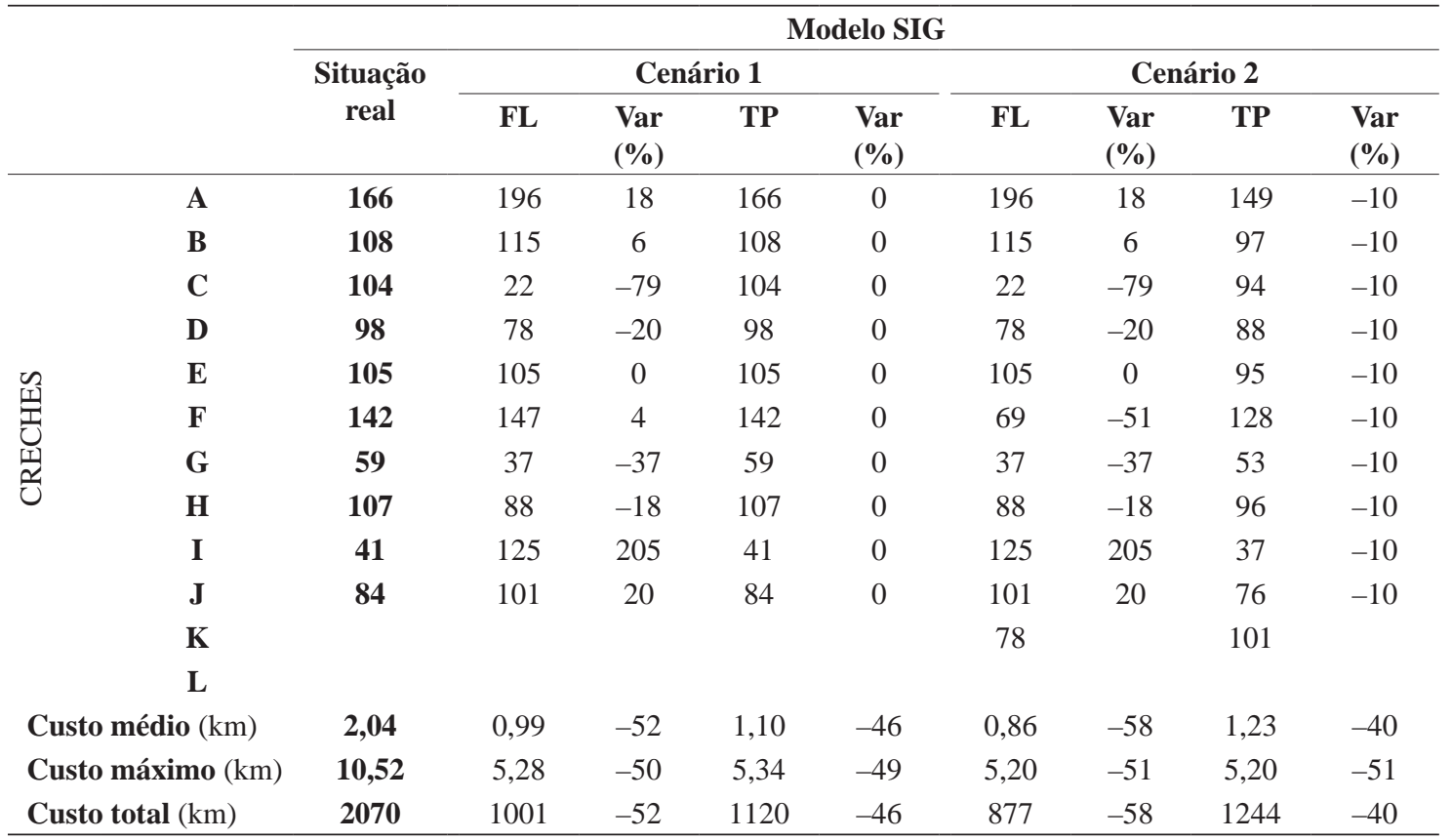


Tabela 8. Resultados dos Cenários 3 e 4 para o modelo SIG para a Simulação III.

\begin{tabular}{|c|c|c|c|c|c|c|c|c|c|c|}
\hline & \multicolumn{9}{|c|}{ Modelo SIG } \\
\hline & & \multirow{2}{*}{$\begin{array}{c}\text { Situação } \\
\text { real }\end{array}$} & \multicolumn{4}{|c|}{ Cenário 3} & \multicolumn{4}{|c|}{ Cenário 4} \\
\hline & & & FL & $\begin{array}{l}\text { Var } \\
(\%)\end{array}$ & TP & $\begin{array}{l}\text { Var } \\
(\%)\end{array}$ & FL & $\begin{array}{l}\text { Var } \\
(\%)\end{array}$ & TP & $\begin{array}{l}\text { Var } \\
(\%)\end{array}$ \\
\hline \multirow{12}{*}{ 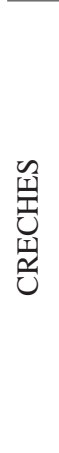 } & $\mathbf{A}$ & 166 & 169 & 2 & 133 & -20 & 196 & 18 & 166 & 0 \\
\hline & B & 108 & 115 & 6 & 86 & -20 & 119 & 10 & 108 & 0 \\
\hline & C & 104 & 22 & -79 & 83 & -20 & fechada & - & fechada & - \\
\hline & D & 98 & 78 & -20 & 78 & -20 & 78 & -20 & 98 & 0 \\
\hline & $\mathbf{E}$ & 105 & 105 & 0 & 84 & -20 & 105 & 0 & 105 & 0 \\
\hline & $\mathbf{F}$ & 142 & 69 & -51 & 114 & -20 & 69 & -51 & 142 & 0 \\
\hline & G & 59 & 37 & -37 & 47 & -20 & 37 & -37 & 59 & 0 \\
\hline & $\mathbf{H}$ & 107 & 88 & -18 & 86 & -20 & 88 & -18 & 107 & 0 \\
\hline & I & 41 & 125 & 205 & 34 & -17 & 143 & 249 & 41 & 0 \\
\hline & $\mathbf{J}$ & 84 & 101 & 20 & 67 & -20 & 101 & 20 & 84 & 0 \\
\hline & $\mathbf{K}$ & & 78 & & 101 & & 78 & & 104 & \\
\hline & $\mathbf{L}$ & & 27 & & 101 & & & & & \\
\hline & io $(\mathrm{km})$ & 2,04 & 0,81 & -60 & 1,09 & -47 & 0,87 & -57 & 1,43 & -30 \\
\hline & imo $(\mathrm{km})$ & 10,52 & 5,20 & -51 & 5,20 & -51 & 5,20 & -51 & 5,57 & -47 \\
\hline & I (km) & 2070 & 822 & -60 & 1102 & -47 & 885 & -57 & 1452 & -30 \\
\hline
\end{tabular}

razão dos valores nulos na penúltima coluna da Tabela 12). Por outro lado, o modelo C/PLIM, gerou localizações diferentes do modelo TP/SIG em todos os cenários em que foi proposta a abertura e/ou fechamento de novas unidades. No Cenário 4 (Figura 8), por exemplo, o modelo SIG localizou a creche $\mathrm{K}$ ao Norte, e o modelo PLIM localizou a creche $\mathrm{M}$ ao Sul, essa última com custo $37 \%$ menor.

\section{Análise geral dos resultados}

Sabe-se que à rotina FL/SIG está associada uma modelagem heurística, e que o modelo NC/PLIM é um modelo exato, garantindo a solução ótima do problema tratado. Visto que a heurística subordinada à rotina FL/SIG produziu soluções com as mesmas localizações e valores de custo total que a solução exata da rotina NC/PLIM, nas três simulações propostas, uma conclusão importante deste trabalho está no desempenho da heurística da rotina FL do software SIG, que pode ser classificada como de boa qualidade, uma vez que esta convergiu para a solução matemática ótima, na totalidade dos cenários simulados.

Além de ter se mostrado uma heurística robusta, a rotina FL/SIG, ao proceder à localização e alocação, otimiza a capacidade das instalações de acordo com a localização da demanda. Citando um exemplo, para o Cenário 1 da Simulação III, no qual buscava-se realocar os alunos às creches existentes, desconsiderando a abertura ou fechamento de unidades, a rotina FL gerou como resultado a melhor alocação entre os alunos e respectivas creches, indicada na Tabela 7 . Sendo assim, as creches deveriam ter suas capacidades projetadas (ou reprojetadas) para atender o número de alunos alocados, indicado pela rotina FL. Se as capacidades de todas as creches fossem redimensionadas para os valores indicados na rotina FL, o modelo SIG geraria uma redução nos custos totais de deslocamento na ordem de $52 \%$, sem a abertura de novas unidades.

Para as Simulações I, II e III, analisando as soluções finais dos cenários, nas quais houve a abertura ou fechamento de novas unidades, o modelo PLIM sempre obteve melhores resultados que o SIG quando se considera a capacidade das instalações. Os menores custos de transporte, com abertura de unidades em locais diferentes, podem ser explicados pelo fato do modelo SIG executar a localização e respectiva alocação (conforme os limites de capacidade máxima) de forma indireta, caracterizando uma desvantagem para o modelo SIG. Na medida em que se vai relaxando a restrição de limite superior de capacidade das instalações, ou seja, ao invés de fixar um valor limite, estabelecer faixas de limite de capacidade, permitindo um aumento de suas capacidades, as soluções geradas pelo modelo SIG tendem a se aproximar das soluções PLIM em termos de alocações fornecedor-cliente. A restrição é relaxada até chegar ao ponto em que o problema se torna não capacitado, em que a solução SIG se iguala à solução PLIM, gerando as mesmas localizações e alocações e, consequentemente, os mesmos valores de custos totais de transporte. Isto ocorre devido às maiores chances que o modelo SIG terá de realocar a demanda à oferta, localizadas anteriormente pela rotina FL, visto que as instalações possuirão um limite superior de capacidade maior, permitindo a alocação de maiores demandas. A Tabela 13 ilustra este fato, apresentando a Simulação II para localização entre CDs e respectivos clientes. 
Para a Simulação II, ao aumentar a faixa de limite de capacidades em $20 \%$ do seu valor inicial e proceder às rotinas capacitadas dos modelos SIG, obtêm-se novas soluções de alocação entre CDs e clientes, como pode ser visto na Tabela 13, quando se compara com

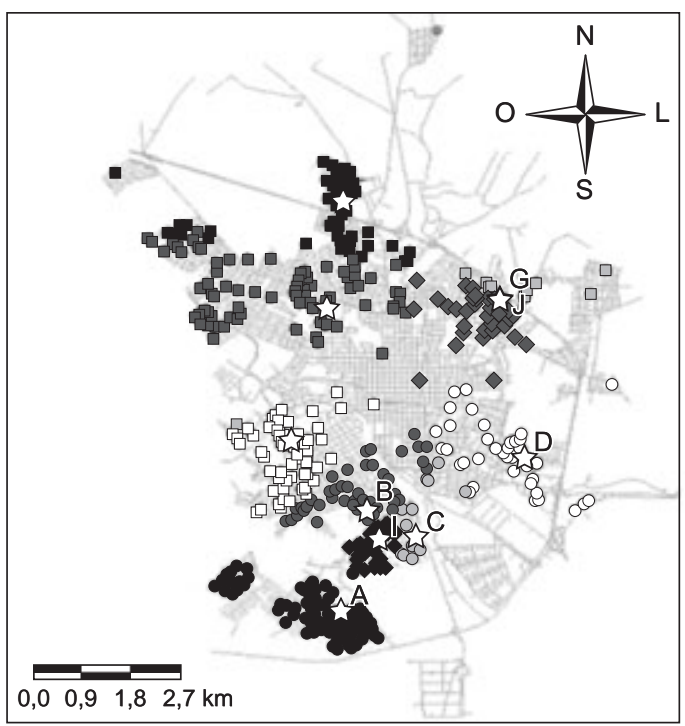

Cenário 1 - FL

- $A(195)$ - B (115) $\circ \mathrm{C}(22) \circ \mathrm{D}(78)$

- $E(105) \square F(147) \square G(37) \square H(88)$

- I (125) ال ال ال (101)

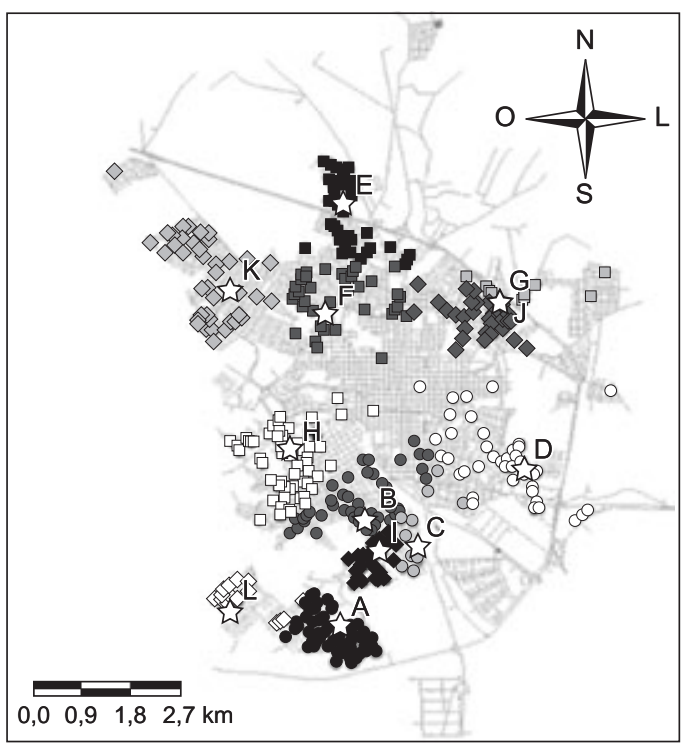

Cenário 3 - FL

- $A(169) \cdot B(115) \circ C(22) \circ D(78)$

- $E(105) \square F(69) \quad \square(37) \square H(88)$

- I (125) $\diamond \mathrm{J}(101) \diamond \mathrm{K}(78) \diamond \mathrm{L}(27)$ a solução apresentada na Tabela 6. Estas diferentes soluções de alocação geram consequentemente distintos valores de Custo Total de serviço. Embora ainda haja diferença entre as soluções de localização e alocação geradas pelos modelos SIG e PLIM com

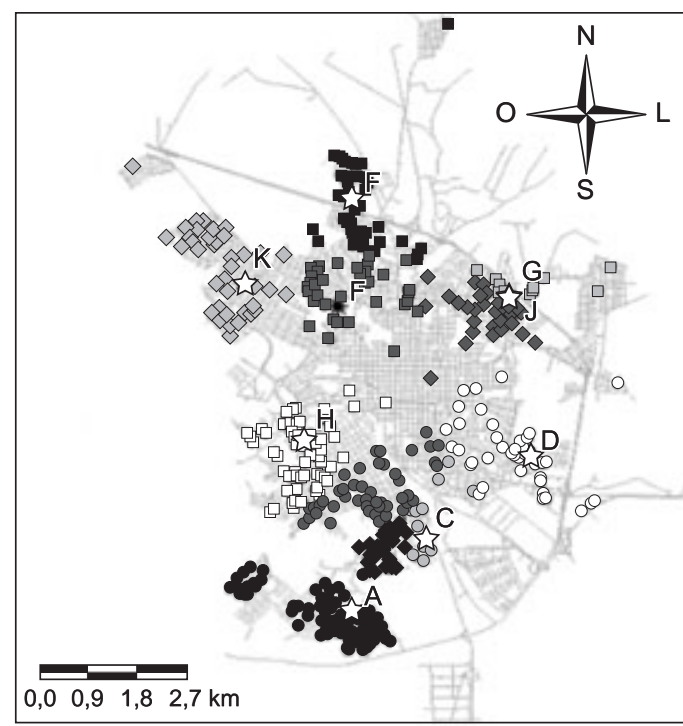

Cenário 2 - FL

- $A(196)-B(115) \circ C(22) \circ D(78)$

- $\mathrm{E}(105) \quad \mathrm{F}(69) \quad \square \mathrm{G}(37) \quad \square \mathrm{H}(88)$

$\bullet \mathrm{I}(125) \diamond \mathrm{J}(101) \diamond \mathrm{J}(78)$

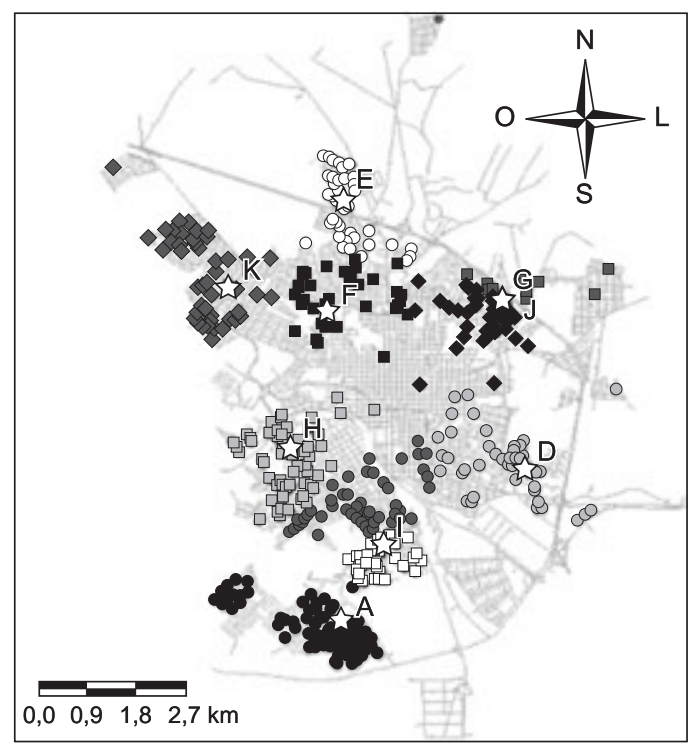

Cenário 4 - FL

- $A(196) \circ B(110) \circ D(98) \circ E(105)$

- $F(142) \quad \square G(59) \quad \square H(107) \square I(41)$

- ل (84) $\quad \mathrm{K}(104)$

Figura 7. Soluções da rotina Facility Location para os distintos cenários na Simulação III. 
Tabela 9. Resultados dos Cenários 1 e 2 para o modelo PLIM para a Simulação III.

\begin{tabular}{|c|c|c|c|c|c|c|c|c|c|c|}
\hline & \multicolumn{9}{|c|}{ Modelo PLIM } \\
\hline & & \multirow{2}{*}{$\begin{array}{c}\text { Situação } \\
\text { real }\end{array}$} & \multicolumn{4}{|c|}{ Cenário 1} & \multicolumn{4}{|c|}{ Cenário 2} \\
\hline & & & NC & $\begin{array}{l}\text { Var } \\
(\%)\end{array}$ & $\mathrm{C}$ & $\begin{array}{l}\text { Var } \\
(\%)\end{array}$ & $\mathrm{NC}$ & $\begin{array}{l}\text { Var } \\
(\%)\end{array}$ & $\mathrm{C}$ & $\begin{array}{l}\text { Var } \\
(\%)\end{array}$ \\
\hline \multirow{14}{*}{ 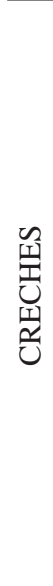 } & $\mathbf{A}$ & 166 & 196 & 18 & 166 & 0 & 196 & 18 & 149 & -10 \\
\hline & B & 108 & 115 & 6 & 108 & 0 & 115 & 6 & 97 & -10 \\
\hline & $\mathrm{C}$ & 104 & 22 & -79 & 104 & 0 & 22 & -79 & 94 & -10 \\
\hline & D & 98 & 78 & -20 & 98 & 0 & 78 & -20 & 88 & -10 \\
\hline & $\mathbf{E}$ & 105 & 105 & 0 & 105 & 0 & 105 & 0 & 95 & -10 \\
\hline & $\mathbf{F}$ & 142 & 147 & 4 & 142 & 0 & 69 & -51 & 128 & -10 \\
\hline & G & 59 & 37 & -37 & 59 & 0 & 37 & -37 & 53 & -10 \\
\hline & H & 107 & 88 & -18 & 107 & 0 & 88 & -18 & 96 & -10 \\
\hline & I & 41 & 125 & 205 & 41 & 0 & 125 & 205 & 37 & -10 \\
\hline & $\mathbf{J}$ & 84 & 101 & 20 & 84 & 0 & 101 & 20 & 76 & -10 \\
\hline & $\mathbf{K}$ & & & & & & 78 & & & \\
\hline & $\mathbf{L}$ & & & & & & & & & \\
\hline & M & & & & & & & & 101 & \\
\hline & $\mathbf{N}$ & & & & & & & & & \\
\hline \multicolumn{2}{|c|}{ Custo médio $(\mathrm{km})$} & 2,04 & 0,99 & -52 & 1,10 & -46 & 0,86 & -58 & 1,08 & -47 \\
\hline \multicolumn{2}{|c|}{ Custo máximo (km) } & 10,52 & 5,28 & -50 & 5,34 & -49 & 5,20 & -51 & 5,28 & -50 \\
\hline \multicolumn{2}{|c|}{ Custo total $(\mathrm{km})$} & 2070 & 1001 & -52 & 1120 & -46 & 877 & -58 & 1095 & -47 \\
\hline
\end{tabular}

Tabela 10. Resultados dos Cenários 3 e 4 para o modelo PLIM para a Simulação III.

\begin{tabular}{|c|c|c|c|c|c|c|c|c|c|c|}
\hline & \multicolumn{9}{|c|}{ Modelo PLIM } \\
\hline & & \multirow{2}{*}{$\begin{array}{l}\text { Situação } \\
\text { real }\end{array}$} & \multicolumn{4}{|c|}{ Cenário 3} & \multicolumn{4}{|c|}{ Cenário 4} \\
\hline & & & $\mathrm{NC}$ & $\begin{array}{l}\text { Var } \\
(\%)\end{array}$ & C & $\operatorname{Var}(\%)$ & $\mathrm{NC}$ & $\begin{array}{l}\text { Var } \\
(\%)\end{array}$ & C & $\begin{array}{l}\text { Var } \\
(\%)\end{array}$ \\
\hline \multirow{14}{*}{ 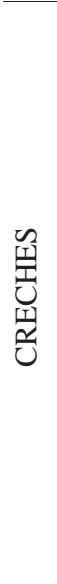 } & A & 166 & 169 & 2 & 133 & -20 & 196 & 18 & 166 & 0 \\
\hline & B & 108 & 115 & 6 & 86 & -20 & 119 & 10 & 108 & 0 \\
\hline & C & 104 & 22 & -79 & 83 & -20 & closed & - & closed & - \\
\hline & D & 98 & 78 & -20 & 78 & -20 & 78 & -20 & 98 & 0 \\
\hline & $\mathbf{E}$ & 105 & 105 & 0 & 84 & -20 & 105 & 0 & 105 & 0 \\
\hline & F & 142 & 69 & -51 & 114 & -20 & 69 & -51 & 142 & 0 \\
\hline & $\mathbf{G}$ & 59 & 37 & -37 & 47 & -20 & 37 & -37 & 59 & 0 \\
\hline & $\mathbf{H}$ & 107 & 88 & -18 & 86 & -20 & 88 & -18 & 107 & 0 \\
\hline & I & 41 & 125 & 205 & 34 & -17 & 143 & 249 & 41 & 0 \\
\hline & $\mathbf{J}$ & 84 & 101 & 20 & 67 & -20 & 101 & 20 & 84 & 0 \\
\hline & $\mathbf{K}$ & & 78 & & 101 & & 78 & & & \\
\hline & $\mathbf{L}$ & & 27 & & & & & & & \\
\hline & M & & & & & & & & 104 & \\
\hline & $\mathbf{N}$ & & & & 101 & & & & & \\
\hline \multirow{3}{*}{\multicolumn{2}{|c|}{$\begin{array}{l}\text { Custo médio }(\mathrm{km}) \\
\text { Custo máximo }(\mathrm{km}) \\
\text { Custo total }(\mathrm{km})\end{array}$}} & 2,04 & 0,81 & -60 & 1,01 & -50 & 0,87 & -57 & 1,05 & -49 \\
\hline & & 10,52 & 5,20 & -51 & 5,20 & -51 & 5,20 & -51 & 5,34 & -49 \\
\hline & & 2070 & 822 & -60 & 1027 & -50 & 885 & -57 & 1063 & -49 \\
\hline
\end{tabular}

Tabela 11. Tempos consumidos no modelo PLIM para a Simulação III.

\begin{tabular}{|c|c|c|c|c|c|c|c|}
\hline \multicolumn{8}{|c|}{ Tempos consumidos no modelo PLIM (hora:minuto:segundo) } \\
\hline \multicolumn{2}{|c|}{ Cenário 1} & \multicolumn{2}{|c|}{ Cenário 2} & \multicolumn{2}{|c|}{ Cenário 3} & \multicolumn{2}{|c|}{ Cenário 4} \\
\hline $\mathrm{NC}$ & $\mathrm{C}$ & $\mathrm{NC}$ & $\mathrm{C}$ & $\mathrm{NC}$ & $\mathrm{C}$ & $\mathrm{NC}$ & $\mathrm{C}$ \\
\hline 00:01:39 & 00:00:48 & 00:01:39 & $00: 42: 46$ & 00:02:56 & $01: 52: 14$ & 00:01:46 & 00:07:50 \\
\hline
\end{tabular}


Tabela 12. Comparação entre os modelos SIG e PLIM para a Simulação III.

\begin{tabular}{|c|c|c|c|c|c|c|c|}
\hline \multirow[b]{2}{*}{ Cenários } & \multirow[b]{2}{*}{ Custos (km) } & \multicolumn{2}{|c|}{ SIG } & \multicolumn{2}{|c|}{ PLIM } & \multicolumn{2}{|c|}{$\operatorname{Var}(\%)$} \\
\hline & & FL & TP & NC & $\mathbf{C}$ & FL vs. NC & TP vs. C \\
\hline \multirow[t]{3}{*}{1} & Custo médio & 0,99 & 1,10 & 0,99 & 1,10 & 0 & 0 \\
\hline & Custo máximo & 5,28 & 5,34 & 5,28 & 5,34 & 0 & 0 \\
\hline & Custo total & 1001 & 1120 & 1001 & 1120 & 0 & 0 \\
\hline \multirow[t]{3}{*}{2} & Custo médio & 0,86 & 1,23 & 0,86 & 1,08 & 0 & 14 \\
\hline & Custo máximo & 5,20 & 5,20 & 5,20 & 5,28 & 0 & -2 \\
\hline & Custo total & 877 & 1244 & 877 & 1095 & 0 & 14 \\
\hline \multirow[t]{3}{*}{3} & Custo médio & 0,81 & 1,09 & 0,81 & 1,01 & 0 & 7 \\
\hline & Custo máximo & 5,20 & 5,20 & 5,20 & 5,20 & 0 & 0 \\
\hline & Custo total & 822 & 1102 & 822 & 1027 & 0 & 7 \\
\hline \multirow[t]{3}{*}{4} & Custo médio & 0,87 & 1,43 & 0,87 & 1,05 & 0 & 37 \\
\hline & Custo máximo & 5,20 & 5,57 & 5,20 & 5,34 & 0 & 4 \\
\hline & Custo total & 885 & 1452 & 885 & 1063 & 0 & 37 \\
\hline
\end{tabular}
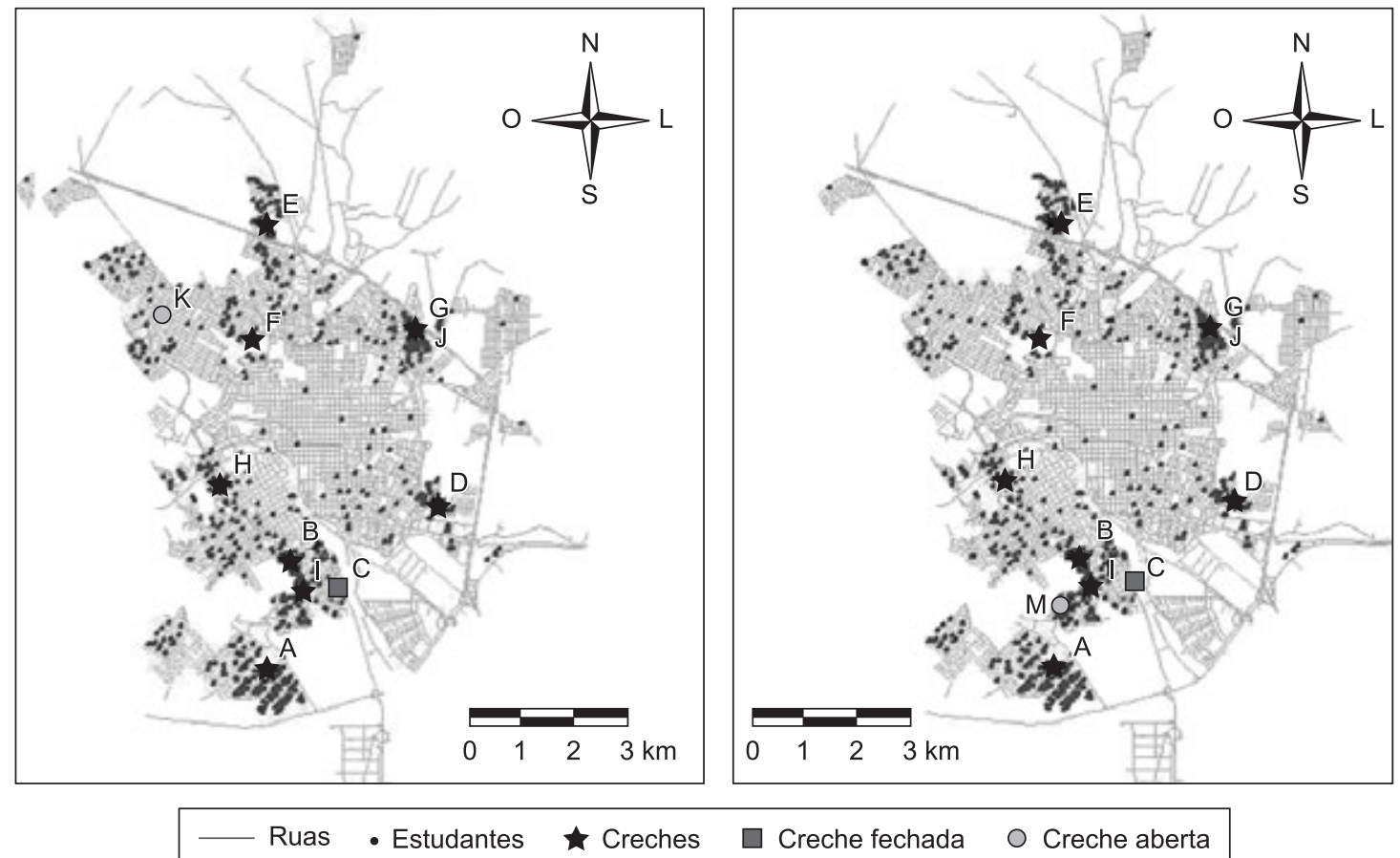

Creche fechada

Creche aberta

Figura 8. Comparação das soluções do Cenário 4 entre os modelos SIG e PLIM.

o aumento do limite de capacidades, a variação entre os dois modelos reduziu-se. Com os valores de limite impostos anteriormente para o Cenário 2 de simulação, por exemplo, a variação entre os dois modelos era de 1,4\% (vide Tabela 6), já com um limite de capacidade $20 \%$ maior, não houve diferença entre os dois modelos. A mesma constatação pode ser averiguada para os Cenários 3 e 4 desta simulação. Testes de limites de capacidades foram também realizados para as Simulações I e III, podendo-se dizer que as conclusões foram as mesmas.
Além disto, há que se considerar que a solução de problemas de localização-alocação de instalações está fortemente relacionada ao conjunto de candidatos à localização. Se este conjunto se altera, a solução do problema tende a se alterar. Sendo assim, quanto maior o número de locais candidatos, melhor deverá ser a qualidade esperada da solução. Porém, um acréscimo do número de variáveis do problema é proporcional a sua complexidade, refletindo no aumento do tempo de processamento computacional consumido para geração da solução. Nesse aspecto, o modelo SIG leva 
Tabela 13. Soluções com o aumento do limite superior de capacidade para a Simulação II.

\begin{tabular}{|c|c|c|c|c|c|c|c|c|}
\hline \multirow[b]{2}{*}{ نُّ } & \multirow[b]{2}{*}{$\begin{array}{c}\text { Limite de } \\
\text { capacidade }\end{array}$} & \multicolumn{3}{|c|}{ SIG } & \multicolumn{3}{|c|}{ PLIM } & \multirow{2}{*}{$\begin{array}{c}\text { Variação } \\
\text { SIG vs. } \\
\text { PLIM } \\
(\%)\end{array}$} \\
\hline & & $\begin{array}{l}\text { Locais para } \\
\text { instalações }\end{array}$ & $\begin{array}{l}\text { Alocação } \\
\text { demanda }\end{array}$ & $\begin{array}{c}\text { Custo } \\
\text { total }\end{array}$ & $\begin{array}{l}\text { Locais para } \\
\text { instalações }\end{array}$ & $\begin{array}{l}\text { Alocação } \\
\text { demanda }\end{array}$ & $\begin{array}{c}\text { Custo } \\
\text { total }\end{array}$ & \\
\hline 1 & 4.634 .323 & A & 3.861 .936 & 820 & A & 3.861 .936 & 820 & 0,0 \\
\hline \multirow[t]{2}{*}{2} & 2.317 .162 & $\mathbf{A}$ & 1.544 .774 & 478 & $\mathbf{A}$ & 1.544 .774 & 478 & 0,0 \\
\hline & & B & 2.317 .162 & & B & 2.317 .162 & & \\
\hline \multirow[t]{3}{*}{3} & 1.544 .774 & $\mathbf{A}$ & 1.544 .774 & 460 & A & 941.708 & 396 & 16,2 \\
\hline & & B & 1.544 .774 & & $\mathbf{F}$ & 1.544 .774 & & \\
\hline & & C & 772.388 & & H & 1.375 .454 & & \\
\hline \multirow[t]{4}{*}{4} & 1.158 .581 & $\mathbf{A}$ & 1.017 .463 & 366 & A & 869.718 & 336 & 8,9 \\
\hline & & C & 527.311 & & $\mathbf{F}$ & 1.158 .581 & & \\
\hline & & D & 1.158 .581 & & B & 1.153 .346 & & \\
\hline & & $\mathbf{E}$ & 1.158 .581 & & $\mathbf{E}$ & 680.291 & & \\
\hline
\end{tabular}

vantagem por ser heurístico, o que permite trabalhar com um número maior de variáveis em um tempo de processamento computacional relativamente curto. Para todos os cenários simulados, o SIG gerou soluções sempre em um tempo inferior a 5 segundos. Já no modelo PLIM, baseado em algoritmo otimizante, o tempo de processamento foi maior, chegando a consumir um máximo de quase 2 horas na rotina com restrição de capacidade (Tabela 11). Para compensar esse tempo de processamento computacional, que se eleva exponencialmente, a solução é a redução no número de variáveis, o que de fato precisou ser feito nas Simulações II e III, de maior porte.

\section{Conclusões}

O objetivo do trabalho foi avaliar a qualidade das soluções para o problema de localização-alocação de instalações geradas por um SIG-T (Sistema de Informação Geográfica para Transportes), obtidas após a utilização combinada das rotinas Localização de Facilidades (FL) e Problema do Transporte (TP), quando comparadas com as soluções ótimas obtidas a partir de modelo matemático exato baseado em Programação Linear Inteira Mista (PLIM), desenvolvido externamente ao SIG. A análise dos resultados mostrou situações diferentes quando são consideradas ou não as restrições impostas pela capacidade das instalações.

Nas rotinas não capacitadas, os modelos SIG e PLIM apresentaram exatamente as mesmas soluções. Daí conclui-se que a heurística do SIG para a rotina FL é bastante eficiente, o que o credencia como uma ferramenta bastante confiável para a utilização em problemas não capacitados, principalmente por sua capacidade de trabalhar com problemas de dimensões maiores. No entanto, ao se considerar as rotinas capacitadas, a resolução do problema pelo modelo combinado do SIG (rotina TP após a rotina FL) leva a resultados diferentes da rotina otimizante do
PLIM, com a indicação de abertura de instalações em locais diferentes. Como os custos de transporte do modelo PLIM chegaram a ser até $37 \%$ menores em uma das simulações efetuadas, conclui-se que este apresenta um melhor desempenho, provavelmente devido à resolução simultânea das fases de localização de instalações e alocação da demanda.

Conforme já mencionado, pesa a favor do SIG a capacidade de lidar com problemas maiores, com um número maior de variáveis e candidatos envolvidos, visto que suas rotinas estão baseadas em heurísticas. A solução otimizante do modelo PLIM está fortemente condicionada ao tamanho do problema a ser resolvido, conforme foi constatado pelos tempos de processamento. Deste modo, sugere-se para trabalhos futuros o desenvolvimento de um novo modelo externo ao SIG, que considere também a resolução simultânea das fases de localização de instalações e alocação da demanda, utilizando-se de um algoritmo heurístico para tal.

\section{Agradecimentos}

Os autores agradecem ao $\mathrm{CNPq}$ (Conselho Nacional de Desenvolvimento Científico e Tecnológico) e à FAPEMIG (Fundação de Amparo à Pesquisa do Estado de Minas Gerais) o apoio financeiro concedido a diversos projetos que subsidiaram o desenvolvimento deste trabalho.

\section{Referências}

ARAKAKI, R. G. I.; LORENA, L. A. N. Uma heurística de localização-alocação (HLA) para problemas de localização de facilidades. Produção, v. 16, n. 2, p. 319-328, 2006.

BALLOU, R. H. Gerenciamento da Cadeia de Suprimentos: Logística Empresarial. 5. ed. Porto Alegre: Bookman, 2006.

BEASLEY, J. Lagrangean heuristics for location problems. European Journal of Operational 
Research, n. 65, p. 383-399, 1993. http://dx.doi. org/10.1016/0377-2217(93)90118-7

BERTRAND, J. W. M.; FRANSOO, J. C. Modelling and simulation: operations management research methodologies using quantitative modeling. International Journal of Operations \& Production Management, v. 22, n. 2, p. 241-264, 2002. http:// dx.doi.org/10.1108/01443570210414338

BIBERACHER, M. GIS-based modeling approach for energy systems. International Journal of Energy Sector Management, v. 2, n. 3, p. 368-384, 2008. http:// dx.doi.org/10.1108/17506220810892937

CARNASCIALI, A. M. S.; DELAZARI, L. S. Integração de Sistemas de Informações Geográficas e Técnicas de inteligência artificial para auxiliar a tomada de decisão locacional do setor bancário. Boletim de Ciências Geodésicas, v. 13, p. 353-368, 2007.

CHURCH, R. L.; SORENSEN, P. Integrating normative location models into GIS: problems and prospects with the p-medianmodel. In: LONGLEY, P.; BATTY, M. (Eds). Spatial Analysis: modeling in a GIS environment. Cambridge: Geo Information International, 1996. p.167-183.

CHURCH, R. L. Geographical Information Systems and location science. Computers \& Operations Research, v. 29, p. 541-562, 2002. http://dx.doi.org/10.1016/ S0305-0548(99)00104-5

DOBRUSKY, F. G. Optimal Location of cross-docking centers for a distribution network in Argentina. 2003. Dissertação (Mestrado em Logística)-Massachusetts Institute of Tecnology, Argentina, 2003.

FLEURY, P. F.; WANKE, P.; FIGUEIREDO, K. F. Logística Empresarial: a perspectiva brasileira. São Paulo: Atlas, 2000.

GU, W.; WANG, X.; GENG, L. GIS-FL Solution: a spatial analysis platform for static and transportation facility locational location problem. In: International Symposiumon Methodologies for Intelligent Systems, 28., 2009, Prague. Proceedings... Prague: Springer LNAI, 2009.

HAMAD, R. Modelo para localização de instalações em escala global envolvendo vários elos da cadeia logística. 2006. Dissertação (Mestrado em Engenharia de Sistemas Logísticos)-Escola Politécnica da Universidade de São Paulo, São Paulo, 2006.

LACERDA, L. Considerações sobre o estudo de localização de instalações. Rio de Janeiro: Centro de
Estudos Logísticos - CEL, Universidade Federal do Rio de Janeiro, 1999. Disponível em: <http://www.cel. coppead.ufrj.br/fs-public.htm>

LIMA, R. S. Bases para uma metodologia de apoio à decisão para serviços de educação e saúde sob a ótica dos transportes. 2003. Tese (Doutorado em Transportes)-Escola de Engenharia de São Carlos, Universidade de São Paulo, São Carlos, 2003.

LORENA, L. A. N. et al. Integração de modelos de localização a Sistemas de Informações Geográficas. Gestão e Produção, v. 8, n. 2, p. 180-195, 2001. http:// dx.doi.org/10.1590/S0104-530X2001000200006

NARUO, M. K. O estudo do consórcio entre os municípios de pequeno porte para disposição final de resíduos sólidos urbanos utilizando Sistemas de Informações Geográficas. 2003. Dissertação (Mestrado em Transportes)-Escola de Engenharia de São Carlos, Universidade de São Paulo, São Carlos, 2003.

OWEN, S. H.; DASKIN, M. S. Strategic facility location: a review. European Journal of Operational Research, n. 111 , p. 423-447, 1998. http://dx.doi.org/10.1016/ S0377-2217(98)00186-6

PIZZOLATO, N. D. et al. Localização de escolas públicas: síntese de algumas linhas de experiências no brasil. Pesquisa Operacional, v. 24, n. 1, p. 111-131, 2004.

PIZZOLATO, N. D.; SILVA, H. B. F. The location of public schools: evaluation of practical experiences. International Transactions in Operational Research, v. 4, n. 1, p. 13-22, 1997. http://dx.doi. org/10.1111/j.1475-3995.1997.tb00058.x

SILVA, M. R. Uma contribuição ao problema de localização de terminais de consolidação no transporte de carga parcelada. Dissertação (Mestrado em Engenharia de Transportes)-Escola Politécnica da Universidade de São Paulo, São Paulo, 2004.

VALLIM FILHO, A. R. A. Localização de centros de distribuição de carga: contribuições à modelagem matemática. Tese (Doutorado em Engenharia de Transportes)-Escola Politécnica da Universidade de São Paulo, São Paulo, 2004.

ZAMBON, K. L. et al. Análise de decisão multicritério na localização de usinas termoelétricas utilizando SIG. Pesquisa Operacional, v. 25, n. 2, p. 183-199, 2005. http://dx.doi.org/10.1590/S0101-74382005000200002 